\title{
Boron Efficient Sugar Beet (Beta Vulgaris L.) Variety Relieve The Symptoms of Boron Deficiency By Enhancing The Antioxidation And Boron Utilization Capacity of The Root System
}

\author{
Xiangling Wang \\ Heilongjiang University \\ Zhenzhen Wu \\ Heilongjiang University \\ Baiquan Song ( $\sim 13212929229 @ 163 . c o m$ ) \\ Heilongjiang University \\ Xiaoyu Zhao \\ Heilongjiang University \\ Xin Song \\ Heilongjiang University
}

\section{Research Article}

Keywords: boron deficiency, sugar beet, root morphology, transcriptome, antioxidant enzymes, transcriptions factor

Posted Date: July 22nd, 2021

DOI: https://doi.org/10.21203/rs.3.rs-727742/v1

License: (c) (i) This work is licensed under a Creative Commons Attribution 4.0 International License.

Read Full License 


\section{Abstract}

(Aims) Sugar beet is one of the most sensitive crops to boron and boron deficiency inhibits the root growth and causes hollow symptoms in beets. However, how the roots of boron efficient sugar beet variety adapt to the morphology, physiological, and transcriptome mechanisms of boron deficiency are rarely reported.

(Method) Thus, the present study was carried out with B efficient sugar beet variety (H, KWS1197) and B inefficient variety ( $L$, KWS0143), and two B levels i.e., $B 0.1\left(0.1 \mu \mathrm{M} \mathrm{H}_{3} \mathrm{BO}_{3}\right.$, deficiency) and $\mathrm{B} 50(50 \mu \mathrm{M}$ $\mathrm{H}_{3} \mathrm{BO}_{3}$, control) were designed for hydroponic experiment.

(Result) Boron deficiency reduced the total root length, root forks, and root biomass of sugar beet. Compared with $\mathrm{L}$ variety, $\mathrm{H}$ variety have higher boron transport coefficient, boron distribution ratio above ground, peroxidase and catalase activities, lower malondialdehyde content and reactive oxygen species accumulation. Transcriptome data showed that the two comparison groups, HB0.1 vs HB50 and LB0.1 vs LB50, were enriched for 537 and 257 differentially expressed genes, respectively. The $\mathrm{H}$ variety mainly induced and regulated the $\mathrm{GO}$ term enrichment associated with antioxidant and stress resistance. On the contrary, the $L$ variety induced cell death and negative regulation of biological and metabolic processes.

(Conclusion) B efficient variety specifically up-regulated boron deficiency response genes to activate the antioxidant enzyme system, promoted rational root configuration, and enhance plant growth antioxidation and resistance to boron deficiency. The results of this study serve as a theoretical basis of screening candidate genes that respond to boron deficiency and adaptation mechanism of boron deficiency.

\section{Introduction}

Sugar beet (Beta vulgaris L.) was one of the most important sugar and cash crops in the world (Song et al., 2019). It is widely planted in Europe, America, and Asia. According to reports, the annual global output of sugar beet was about 172 million tons per year (Porcel et al., 2018). Beetroot was not only used in the food industry (Evans and Messerschmidt, 2017), but also as a renewable energy source (Magaña et al., 2011) for the production of bioethanol (Zabed et al., 2014).Boron (B) is a micronutrient element indispensable for the growth and development of higher plants and has properties between metals and non-metals (Warington, 1923; Nable, 1997).

Root morphology is a critical factor affecting crop yield and the root system was the first part to perceive the signal during nutrient stress (Schachtman, 2008). The root system adapted to the stress by activating the antioxidant system and regulating protein synthesis (Hu et al., 2018; Zhang et al., 2015). Boron deficiency led to severe reductions in crop yields (Sillanpaa, 1990; Shireen et al., 2018) and destroyed the structure and function of cell walls and plasma membranes, disrupted physiological and metabolic processes such as secondary metabolism, oxidative stress, and gene expression (Camacho et al., 2008; González-Fontes et al., 2008), thereby inhibiting root system development (Pang et al., 2010; Doblin et al., 
2010; Huang et al., 2021). Generally, $B$ was absorbed by plants in the form of boric acid $\left(\mathrm{H}_{3} \mathrm{BO}_{3}\right)$ through passive diffusion (Raven, 1980; Dordas and Brown, 2000). However, in the absence of B, plants transport boron from soil to roots by inducing aquaporins (NIPs, nodulin26-like intrinsic protein (Roberts and Rouray, 2017; Granado, 2020) and the BOR family of borate transporters, then load B into the xylem for further transportation.

Transcriptomics was widely used to study plant responses to various stresses (Imadi et al., 2015), which can obtain differentially expressed genes (DEGs) based on changes in genotype or growth environment between species (Mazzitelli et al. 2017). In recent years, more and more studies have used RNA sequencing (RNA-seq) to reveal the molecular response mechanism of a variety of crops under abiotic stress (Jiang, et al., 2020). The publication of the sequencing of the sugar beet genome makes sugar beet an excellent model crop for studying plant responses to various stresses (Dohm et al. 2014). At present, it has been reported that sugar beets have been exposed to salt stress (Yu et al., 2020; Liu et al., 2020; Lv et al., 2018; Kito et al., 2017), alkali stress (Hossain et al. 2017) and cold stress (Moliterni et al. al, 2015) under the transcriptome research. Studies have shown that in the same species, compared with sensitive variety, resistant variety has a more complex transcriptional response, and can enrich with more DEGs numbers and metabolic pathways (Guo et al., 2020; Amirbakhtiar et al., 2019; Hua et al., 2016). However, as far as sugar beet is concerned, there is limited information on the transcriptional regulation of sugar beet roots with different boron efficiency under boron deficiency. In this study, transcriptome studies were conducted on the roots of boron-efficient and boron-inefficient sugar beet variety under the stress of boron deficiency to analyze the root morphology, physiology, and molecular mechanisms of borondeficiency tolerance in boron-efficient sugar beet variety, and to reveal the physiological and metabolic processes involved in boron deficiency stress. These results not only provide a new understanding of the morphological changes and transcriptional response of different boron-efficiency sugar beet roots to boron deficiency stress, but also lay a theoretical basis for the breeding of boron-deficiency tolerant sugar beet germplasm.

\section{Materials And Methods}

\subsection{Experimental design, plant material, and treatments}

The experiment was carried out in the artificial light cultivation room of the National Sugar Improvement Center (Harbin, China) in August 2019, located (longitude: 126 ${ }^{\circ} 37^{\prime}$, latitude: $45^{\circ} 43^{\prime}$ ). The test material had boron efficient variety "KWS1197" (H) and boron inefficient sugar beet variety "KWS0143" (L) purchased from KWS company (KWS SAAT SE \& Co. KGaA, Germany). Before sowing, rinse the seeds in running water for $6 \mathrm{~h}$, then transfer to $75 \%$ alcohol to rinse for $1 \mathrm{~min}$, and finally transfer to $2 \%$ o of thiram solution to soak for $12 \mathrm{~h}$, then washed with distilled water 3 times, and finally sown in high-temperature sterilized vermiculite.

The seedlings with the same growing vigor were selected when the cotyledons of sugar beet are fully expanded for the hydroponic experiment. The $2 \mathrm{~L}$ polyethylene plastic nursery pot (covered with black 
shading paper) was used to cultivate a sugar beet seedling, and the nutrient solution was replaced every 7 days. The Hoagland nutrient solution (Hoagland and Arnon. 1950) applied for cultivation and nutrient solution contained $1.35 \mathrm{M} \mathrm{Ca}\left(\mathrm{NO}_{3}\right)_{2} \cdot 4 \mathrm{H}_{2} \mathrm{O}, 1.01 \mathrm{M} \mathrm{KNO}_{3}, 0.4 \mathrm{M} \mathrm{MgSO}_{4} \cdot 7 \mathrm{H}_{2} \mathrm{O}, 0.12 \mathrm{M} \mathrm{K}_{2} \mathrm{HPO}_{4}, 0.15 \mathrm{M}$ $\mathrm{KH}_{2} \mathrm{PO}_{4}, 0.02 \mathrm{M} \mathrm{Fe}$-EDTA, $0.32 \mathrm{mM} \mathrm{CuSO}_{4} .5 \mathrm{H}_{2} \mathrm{O}, 0.33 \mathrm{mM}\left(\mathrm{NH}_{4}\right)_{6} \mathrm{MO}_{7} \mathrm{O}_{24}, 7.74 \mathrm{mM} \mathrm{MnCL} 2.4 \mathrm{H}_{2} \mathrm{O}$, and $0.77 \mathrm{mM} \mathrm{ZnSO}_{4} .7 \mathrm{H}_{2} \mathrm{O}$. All chemicals used were of high grades and purity, and the water for the experiment was deionized. The $0.1 \mathrm{M} \mathrm{H}_{2} \mathrm{SO}_{4}$ or $0.1 \mathrm{M} \mathrm{NaOH}$ was used to adjust the $\mathrm{pH}$ of the nutrient solution at 6.50 every three days. First seedlings were grown in $1 / 4$ strength and then $1 / 2$ strength, finally, full strength nutrient solution. The seedlings were harvested after 14 days of cultivation. The experiment had two boron treatments i.e., B-deficiency $\left(0.1 \mu \mathrm{M} \mathrm{H}_{3} \mathrm{BO}_{3}\right.$ ) and normal boron (control, $50 \mu \mathrm{M} \mathrm{H}_{3} \mathrm{BO}_{3}$ ). The four experimental treatments were named: HB0.1, HB50, LB0.1, and LB50 and each treatment had 25 biological replicates. The aeration was provided twice a day for two hours each time. The relative humidity in the artificial incubation room was $65 \%$, the temperature was $24^{\circ} \mathrm{C} / 20^{\circ} \mathrm{C}$ (day/night), and the photoperiod was 12h/12h (light/dark).

\subsection{Measurement of plant biomass, root morphological characteristics, and RNA-Sequencing (RNA-Seq)}

Root scanning tests were carried out on the $1,3,5$, and 7 days of the boron deficiency stress treatment. The plants were divided into two parts: shoot and root. The fresh weight (FW) was measured and then dried in an oven at $65^{\circ} \mathrm{C}$ to a constant weight, the dry weight (DW) of each part of the plant was recorded under different boron treatments, each treatment contained 4 biological replicates. Fresh roots were scanned with a root analyzer (Epson Perfection V700) and analyzed the data with Winrhizo root analysis system (WinRHIZO, Regent Instruments Inc., Canada) to obtain total root length (TRL), total surface area (TSA), root forks (RFs), root volume (RV) and root average diameter (RAD). The appendix provided specific steps for histochemical staining (DAB and NBT) of sugar beet roots.

The root system of the lower $1 / 3$ part of each treatment beet was cut and mixed, and later frozen in liquid nitrogen for 20 minutes, and then it was quickly transferred to a refrigerator at $-80^{\circ} \mathrm{C}$ for sample storage. Each boron treatment included 3 biological replicates for determining resistance antioxidative system and transcriptome sequencing. Root length ratio (RLR), root fineness (RF), root mass ratio (RMR), root tissue density (RTD), specific root length (SRL), and specific root area (SRA) were calculated by the following equations (Ali et al., 2018):

- Root length ratio $(R L R)=$ total root length/whole plant dry weight $\left(m \cdot \mathrm{g}^{-1}\right)$.

- Root fineness $(\mathrm{RF})=$ total root length/root volume $\left(\mathrm{cm} \mathrm{cm}^{-3}\right)$.

- Root mass ratio $(\mathrm{RMR})=$ root dry weight/whole plant dry weight $\left(\mathrm{g} \mathrm{g}^{-1}\right)$.

- Root tissue density (RTD) = root dry weight/root volume $\left(\mathrm{mg} \mathrm{cm}^{-3}\right)$.

- Specific root length $(\mathrm{SRL})\left(\mathrm{km} \mathrm{g}^{-1}\right)=$ total root length / root dry weight

- Specific root area (SRA) $\left(\mathrm{cm}^{2} \mathrm{mg}^{-1}\right)=$ total surface area / root dry weight 


\subsection{Antioxidant enzyme system index determination and histochemical staining of root system}

The $0.5 \mathrm{~g}$ of fresh root samples were homogenized in $5 \mathrm{ml}$ of $0.05 \mathrm{M}$ phosphate-buffered saline (PBS) at $\mathrm{pH} 7.8$ to a pre-cooled mortar (sampling process is the same as the transcriptome) into a homogenate and centrifuged at $15000 \mathrm{rpm}$ at $4^{\circ} \mathrm{C}$ for $15 \mathrm{~min}$. The supernatant was stored in a refrigerator at $4^{\circ} \mathrm{C}$ for testing.

Nitrogen blue tetrazolium reduction method (Beauchamp and Fridovich, 1971) to measure the SOD enzyme activity. The total reaction system had $3 \mathrm{ml}$ mixture, and the OD value of $50 \mu \mathrm{l}$ enzyme solutions were measured at $560 \mathrm{~nm}$ to calculate the SOD enzyme activity. The guaiacol method (Cakmak et al., 1991) was used to measure the OD value of $50 \mu \mathrm{l}$ enzyme solutions at $470 \mathrm{~nm}$, the change rate within $210 \mathrm{~s}$ was record, and calculated the POD enzyme activity. According to the method described by De Azevedo Neto (De Azevedo Neto et al., 2006), $50 \mu \mathrm{l}$ enzyme solutions were measured at $240 \mathrm{~nm}$ and the OD value change rate in 210 s was recorded to calculate the CAT enzyme activity. Vos (Vos et al., 1991) method was referred to prepare $4 \mathrm{ml}$ total reaction system which had $1.5 \mathrm{~mL}$ of the enzyme solutions in a glass test tube with a stopper, and $2.5 \mathrm{~mL} 0.5 \%$ thiobarbituric acid (TBA) solution. After mixing, the samples were reacted in a boiling water bath for $20 \mathrm{~min}$, and then the samples were cooled to room temperature and centrifuged at $15000 \mathrm{rpm}$ at $4^{\circ} \mathrm{C}$ for 15 minutes. The OD values were recorded at the wavelengths of $532 \mathrm{~nm}, 600 \mathrm{~nm}$, and $450 \mathrm{~nm}$, and calculate the content of malondialdehyde (MDA) according to the formula.

MDA content $\left(\mu \mathrm{mol} \cdot \mathrm{g}^{-1} \mathrm{FW}\right)=\frac{\left[6.45\left(O D_{532}-O D_{600}\right)-0.56 O D_{450}\right] \times V}{m \times 10^{3} \times V_{t}}$

Note: $V$ is the total enzyme volume of $5 \mathrm{ml}$, and $V_{t}$ is the volume of $1.5 \mathrm{ml}$ enzyme solution used to determine the content of malondialdehyde.

The 3,3-Diaminobenzidine (DAB) staining method is used to detect the accumulation of $\mathrm{H}_{2} \mathrm{O}_{2}$ in the root tips and taproot, and the roots are cultured in DAB staining buffer $(0.1 \mathrm{mg} / \mathrm{ml} \mathrm{DAB}, 0.5 \mathrm{M}$ phosphate buffer, $\mathrm{pH}$ 7.5) $1 \mathrm{~h}$. For nitronitroblue tetrazolium (NBT) staining to detect $\mathrm{O}_{2}{ }^{-}{ }^{-}$, incubate in NBT staining buffer $(0.1 \mathrm{mg} / \mathrm{ml} \mathrm{NBT}, 0.5 \mathrm{M}$ phosphate buffer, $\mathrm{pH} 7.5)$ for $1 \mathrm{~h}$ at room temperature. Both DAB staining buffer and NBT staining buffer are newly prepared and stored at $4^{\circ} \mathrm{C}$ in the dark. Samples stained with DAB or NBT were washed twice with $0.5 \mathrm{M}$ phosphate buffer (PBS), stored in $70 \%$ ethanol for 30 minutes, and photographed with a stereo microscope (SteREO Discovery.V8, ZEISS, Beijing, China).

\subsection{Determination of boron content in sugar beet plants}

Boron content in plants was determined by curcumin colorimetry (Dible et al., 1954). The $0.2 \mathrm{~g}$ of dry samples (DW) of shoots and roots ground were ground to a uniform powder (passed through a 40-mesh sieve), and put in a muffle furnace to carbonize at $240^{\circ} \mathrm{C}$ for $1 \mathrm{~h}$, then adjust the temperature of the muffle furnace to $560^{\circ} \mathrm{C}$, continued ashing for $4 \mathrm{~h}$. The $B$ was extracted with $10 \mathrm{~mL}$ of $0.1 \mathrm{M} \mathrm{HCl}$ for 30 
min and filtered it as the test solution. The $1 \mathrm{ml}$ of the test solution was pipetted into an evaporating dish, and $5 \mathrm{ml}$ of curcumin-oxalic acid solution added and, shaked well and placed gently in a $54^{\circ} \mathrm{C}$ water bath to evaporate to dryness, and then continued heating for $20 \mathrm{~min}$ (total evaporation time was about 45 $\mathrm{min}$ ). The $10 \mathrm{~mL}$ of $95 \%$ ethanol was used to wash the evaporating dish several times in small amounts, filtered, and measured the OD at $540 \mathrm{~nm}$ by double-beam UV-spectrophotometer (UV-8000A, Shanghai, China). The $95 \%$ ethanol was used as a blank. The calculation formulae are as following:

- Boron accumulation $\left(\mu\right.$ g plant $\left.^{-1}\right)=B$ content $\left(\mu \mathrm{g} \mathrm{g}^{-1}\right) \times$ corresponding dry weight $\left(\right.$ g plant $\left.^{-1}\right)$

- Boron transport coefficient $=$ aboveground $\mathrm{B}$ accumulation $\left(\mu\right.$ plant $\left.^{-1}\right) /$ underground $\mathrm{B}$ accumulation $\left(\mu\right.$ plant $\left.^{-1}\right)$

- Boron use efficiency $\left(\mathrm{g} \mathrm{\mu g}^{-1}\right)=$ plant dry weight $\left(\mathrm{g} \mathrm{plant}^{-1}\right) /$ plant boron accumulation $\left(\mu \mathrm{g} \mathrm{plant}^{-1}\right)$

\subsection{Enrichment analysis of DEGs, GO terms and KEGG categories}

In order to screen and enrich the differential expressedgene(DEGs) in response to boron deficiency, two comparison groups were constructed, namely HB0.1 vs HB50 and LB0.1 vs LB50. Download the sugar beet reference genome from the genome website (https://bvseq.boku.ac.at/index.shtml), the version was RefBeet-1.2.2. $p$ value $<0.05$ and $\log _{2}$ (fold change) $\geq+1$ or $\log _{2}$ (fold change) $\leq-1$ was considered as the screening condition for DEGs. In order to identify the possible biological processes or pathways involved in the response to boron deficiency, GO term and KEGG pathway function enrichment were performed. Gene Ontology (GO) enrichment analysis divides genes and gene products into three categories (Young et al,2010) (i) molecular function (MF); (ii) cellular component (CC); (iii) biological process (BP). The Kyoto Encyclopedia of Genes and Genomes (KEGG) Pathway database records the network of molecular interactions in cells and variants of them specific to particular organisms (Thimm et al., 2004). Pathwaybased analysis was used to further understand the biological functions and interactions of the gene.

\section{6 qRT-PCR verification of DEGs in the transcriptome}

In order to verify the accuracy of the RNA-Seq data, 14 randomly selected DEGs were analyzed by qRTPCR. Primer Express 5.0 (Premier Biosoft Interpairs, Palo Alto, CA) was used to design primers. The sequence of the primers was listed in Table S1. Plant Polysaccharide Polyphenol Extraction Kit (DP441, Tiangen, Beijing, China) was used to extract total RNA from root samples, and FastKing one-step method was used to remove genomic cDNA first-strand synthesis premix reagent, the cassette (KR118-02, Tiangen, Beijing, China) performs reverse transcription to synthesize the first-strand CDNA. The PCR products were detected by gel electrophoresis to check the specificity of gene primers. The relative expression levels of genes were detected by the Mx3000P real-time PCR system (Angelent, La Jolla, CA, USA) instrument and the Super Real PreMix Plus (Beijing Tianjian, China) kit was used for the qRT-PCR test. Each cDNA sample was performed three technical replicates. The $20 \mu \mathrm{L} \mathrm{qPCR}$ reaction system contained $1 \mu \mathrm{L} \mathrm{cDNA}, 1.2 \mu \mathrm{L}$ primer pair mixture $(10 \mu \mathrm{M}), 0.4 \mu \mathrm{L} 50 \times$ reference dye, $7.4 \mu \mathrm{L}$ RNase-free 
$\mathrm{ddH} 2 \mathrm{O}$ and $10 \mu \mathrm{L} 2 \times$ SuperReal PreMix Plus. The qPCR reaction program using the SYBR Green I method is as follows: initial denaturation at $95^{\circ} \mathrm{C}$ for 10 minutes, then 40 cycles: $95^{\circ} \mathrm{C}$ for $10 \mathrm{~s}, 60^{\circ} \mathrm{C}$ for $20 \mathrm{~s}$ and $72^{\circ} \mathrm{C}$ for $30 \mathrm{~s}$, followed by a melting curve analysis and measured whether the expression level was normal according to the expression of the housekeeping gene GAPDH, and checked the specificity of the amplified fragment according to the generated melting curve. The $2^{-\Delta \Delta C t}$ method was used to analyze the relative expression of genes (Livak and Schmittgen 2001).

\subsection{Statistical Analysis}

SPSS 22.0 (SPSS Inc, Chicago, IL) software was used to conduct two-factor random analysis of variance (two-way ANOVA) and minimum significant difference method (LSD) at $p<0.05$. Origin 2019b (origin $2019 \mathrm{~b}$ Inc, USA) was used to draw the bar chart, line chart, and the level of significance was set to $p=$ 0.05 or $p=0.01$. Significant and extremely significant differences were expressed by "*" and "**".

\section{Results}

\subsection{Effect of boron deficiency treatment on the growth characteristics and biomass of sugar beet}

Figure $1 \mathrm{~A}$ showed the growth of plants after 7 days of boron deficiency, the results showed that boron deficiency significantly inhibited the normal growth of sugar beet, which was manifested by the reduction of root elongation and root forks and promoted the occurrence of lateral roots (Fig. 1B), and as the stress time increased, the difference between the boron treatments was more obvious. Boron deficiency led to a decrease in the total root length (Fig. 1C), root volume (Fig. 1D), and number of root tips (Fig. 1E) of the plant root system, increasing the average root diameter (Fig. 1F). Further analysis of the root scan data showed that boron deficiency significantly reduced the root fineness (RF) of the plant (Fig. S2B), and the $H$ and $L$ varieties were reduced by $38 \%$ and $62 \%$, respectively. Boron deficiency reduced the root length ratio (RLR), root mass ratio (RMR), root tissue density (RTD), and specific root length (SRL) of sugar beet plants (Fig. S2A, 2C, 2D, 2E), resulting in a decrease of $28.0 \%, 12.0 \%, 22.0 \%$ and $21 \%$ in $\mathrm{H}$ variety, respectively; but increased the specific root surface area (SRA) of $L$ variety $(27.8 \%)$, while the specific root surface area of $\mathrm{H}$ variety hardly changed (Fig. S2F).

As shown in Fig. 2, boron deficiency significantly reduced the root dry weight $(25.03 \%$ and $34.39 \%)$ and root-shoot ratio $(24.91 \%$ and $22.53 \%$ ) of $\mathrm{H}$ and $\mathrm{L}$ variety, and boron deficiency also significantly reduced the shoot dry weight $(14.98 \%)$ and total plant dry weight $(17.96 \%)$ of $L$ variety, while the shoot dry weight $(0.66 \%)$ and total plant dry weight $(4.76 \%)$ of $\mathrm{H}$ variety were not significant. The results showed that under the treatment of boron deficiency, the above-ground dry weight and total plant dry weight of $\mathrm{H}$ and $L$ varieties showed extremely significant differences. However, the root dry weight and root-shoot ratio of the two sugar beet varieties showed no significant difference. 


\subsection{Responses of the antioxidant enzyme system in the roots of different boron-efficiency sugar beet cultivars to boron deficiency}

Boron deficiency significantly increased the POD (21\%) and CAT (69\%) enzyme activities of H variety and decreased the SOD enzyme activity (0.5\%) (Fig. 3A-3C). Boron significantly reduced the enzyme activities of SOD (12\%), POD (19\%) and of L varieties, and extremely significantly reduces the enzyme activity of CAT (74\%). Under the two-boron treatments, the MDA content in the roots of the $\mathrm{H}$ variety was significantly lower than that of the $L$ variety (Fig. 3D); The MDA content of $H$ and $L$ varieties under boron deficiency treatment were $0.32 \mu \mathrm{mol} \mathrm{g}{ }^{-1} \mathrm{FW}$ and $0.42 \mu \mathrm{mol} \mathrm{g}{ }^{-1} \mathrm{FW}$, respectively, and under normal boron treatment they were $0.21 \mu \mathrm{mol} \mathrm{g}{ }^{-1} \mathrm{FW}$ and $0.28 \mu \mathrm{mol} \mathrm{g}-1 \mathrm{FW}$, respectively.

Histochemical staining of the root tips and taproots of sugar beet varieties with different boron efficiency under two boron treatments was carried out to clarify the accumulation of superoxide anion $\left(\mathrm{O}_{2}{ }^{\cdot-}\right)$ and hydrogen peroxide $\left(\mathrm{H}_{2} \mathrm{O}_{2}\right)$ (Fig. 4). Boron deficiency resulted in a large accumulation of $\mathrm{O}_{2}^{\cdot-}$ and $\mathrm{H}_{2} \mathrm{O}_{2}$ in the root tips and taproots. It was found that the accumulation of $\mathrm{H}_{2} \mathrm{O}_{2}$ and $\mathrm{O}_{2} \cdot{ }^{\cdot-}$ in boron-inefficiency sugar beet variety was significantly more serious than that of boron-efficient variety, indicating that boron deficiency stress caused the root system has severe oxidative damage. At the same time, the taproots of sugar beet under different treatments were observed, and it was found that compared with normal boron treatment, the dyeing range under the boron deficiency treatment was larger, the color was darker, and more dyes were accumulated, but compared with the inefficient boron variety, Whether it is DAB dyeing or NBT dyeing, the efficient boron variety have a lighter degree of dyeing under the treatment of boron deficiency, indicating that the efficient boron variety have strong antioxidant capacity.

\subsection{Responses of different boron-efficiency sugar beet varieties to boron accumulation and boron allocation rate to boron deficiency}

Boron deficiency significantly reduced the boron accumulation in the shoots and roots of the two sugar beet varieties, resulting in $87 \%$ and $90 \%$ reductions in the boron accumulation in the shoots, respectively (Fig. 5A). The accumulation of $B$ in roots was reduced by $61 \%$ and $47 \%$, respectively (Fig. 5B). Regardless of boron deficiency or normal boron treatment, the total boron accumulation of $\mathrm{H}$ variety was lower than that of $L$ variety. Boron deficiency reduced the total boron accumulation of the two varieties by $86 \%$ and $88 \%$, respectively (Fig. 5C). Secondly, boron deficiency significantly reduced the boron transfer coefficient (BTC) of the two sugar beet varieties. Under the treatment of boron deficiency, the BTC values of the two sugar beet varieties were 6.07 and 4.46, respectively (Fig. 5D), indicating that the $\mathrm{H}$ variety has higher boron transport ability. In addition, the lack of boron greatly improved the boron utilization efficiency of the two varieties (Fig. 5E). Under the two boron treatments, the boron utilization coefficient of the $\mathrm{H}$ 
variety was lower than that of the $\mathrm{L}$ variety, which indicated that with a small amount of dry matter, the $\mathrm{H}$ variety could induce more boron accumulation. Further analysis of the boron distribution rate in plant roots and shoots showed that in the case of boron deficiency, $\mathrm{H}$ varieties can transport more boron nutrients to the ground (Fig. 5F).

\subsection{Overview of transcriptome data by RNA-Seq analysis}

By using PE150 sequencing strategy, a total of 563551518 raw data were obtained, and 556750800 net readings and 10467 single genes were obtained after quality control. After removing the joint contamination and low-quality Reads, more than 21398452 valid original readings were obtained from $\mathrm{H}$ and $L$ variety, and high-quality readings exceeding 21138827 were obtained for each treatment (Table 1); GC content was distributed in $92.49 \%$ and $92.61 \%$. Among them, the ratio of Q20 was above $97.26 \%$, and the ratio of Q30 was above $42.60 \%$. All treatments had high-quality readings of more than $93.31 \%$, which can be used to further analyze the transcriptome of sugar beet roots under boron deficiency stress.

Table 1

Overview of the sequencing data

\begin{tabular}{|l|lllll|}
\hline Treatment & HB0.1 & HB50 & LB0.1 & LB50 \\
\hline Raw reads & 22929563 & 21398452 & 23381927 & 23388852 \\
\hline Clean reads & 22625066 & 21138827 & 23092111 & 23036696 \\
\hline Total reads & 45250131 & 42277654 & 46184222 & 46073391 \\
\hline Total mapped (\%) & 93.31 & 95.61 & 93.99 & 95.71 \\
\hline Uniquely mapped (\%) & 90.20 & 92.62 & 91.12 & 93.00 \\
\hline GC content (\%) & 92.49 & 92.61 & 92.56 & 92.58 \\
\hline Q20 ratio (\%) & 97.26 & 97.32 & 97.29 & 97.31 \\
\hline Q30 ratio (\%) & 42.60 & 42.85 & 42.70 & 42.87 \\
\hline
\end{tabular}

Two comparison groups were constructed to analyze the transcriptome data, and it was found that 537 and 257 DEGs existed in the HB0.1 vs HB50 and LB0.1 vs LB50 comparison groups, respectively (Fig. 5). The results showed that there were significant differences in gene expression levels between the two varieties between normal boron control treatment and boron deficiency treatment (Fig. 6). Among them, there were 237 up-regulated DEGs and 300 down-regulated DEGs in the HB0.1 vs HB50 comparison group, while there were 122 up-regulated DEGs and 135 down-regulated DEGs in the LB0.1 vs LB50 comparison group. Among them, 88 co-expressed genes (18 co-up-regulated DEGs and 59 co-downregulated DEGs) were shown between two comparison groups.

\subsection{Enrichment analysis of GO term and KEGG pathway}


Through GO term functional enrichment analysis, 288 differentially expressed $\mathrm{GO}$ terms were found in the HB0.1 vs HB50 comparison group. The results showed "response to oxidative stress" (G0:0006979, 3 upregulated and 3 down-regulated genes), "peroxidase activity" (G0:0004601, 3 up-regulated and 3 downregulated genes) and "thylakoid light-harvesting complex" (G0:0009503, 1 up-regulated gene) were the most significantly enriched GO among biological process (BP), molecular function(MF) and cellular component(CC). In the LB0.1 vs LB50 comparison group, 142 differentially expressed GO terms were found, "apoptotic process" (G0:0006915, 11 up-regulated genes and 1 down-regulated gene), "obsolete toxin activity" (G0:0015070, 4 up-regulated genes and 3 down-regulated genes) and "transcription factor TFIID complex" (GO:0005669, 4 down-regulated genes) were the most abundant GO techniques in BP, MF and $\mathrm{CC}$ ontology, indicating that the genes involved in these processes may be missing which play a key role in the response to boron stress. Interestingly, in the two comparison groups, neither the up-regulated expression of DEGs involved in cell components was enriched, and only partially down-regulated DEGs were enriched in the $L$ variety. Secondly, the $G O$ categories such as antioxidant activity, peroxide and oxidoreductase activity in the HB0.1 vs HB50 comparison group showed an up-regulated trend, while the LB0.1 vs LB50 comparison group had negative effects on cell processes, biological processes, and metabolic processes; and up-regulated cell death and programmed cell death $\mathrm{GO}$ categories. The adjustment process showed an upward trend, which may be related to the stronger antioxidant capacity of $\mathrm{H}$ variety.

In order to further analyze the functions of DEGs involved in the response to boron deficiency, the KEGG database was used to screen the differentially expressed genes enriched in different metabolic pathways. In the KEGG pathway analysis, the enriched DEGs in the HB0.1 vs HB50 and LB0.1 vs LB50 comparison groups were divided into 68 and 47 functional categories, respectively $(p<0.05$ as the screening threshold for KEGG functional enrichment). The study found that the number of DEG involved in the metabolic pathway was the highest (bvg01100), 50 and 25 DEG in the two comparison groups, respectively. Phenylpropanoid biosynthesis (14 DEGs) and fructose and mannose metabolism (3 DEGs) were the significantly enriched KEGG pathways in the two comparison groups HB0.1 vs HB50 and LB0.1 vs LB50, respectively.

\subsection{Responses of antioxidant enzyme-related genes in sugar beet roots to boron deficiency stress}

The results of the expression of candidate genes related to antioxidant enzymes involved in the response to boron deficiency revealed that in the $\mathrm{H}$ variety, there were 6 up-regulated genes and 1 down-regulated gene (Fig. 9). The expression of SOD-related genes (LOC104902979) was highly down-regulated between the two comparison groups. The lowest expression level of the gene was -0.953 in the LB0.1 vs LB50 comparison group, the expression level of this gene in the HB0.1 vs HB50 comparison group was -0.860 . POD-related genes (LOC104908142, LOC104895312 and LOC104895166) were highly up-regulated in the HB0.1 vs HB50 comparison group, compared with boron deficiency treatment, these gene expression levels were $3.841,1.542$ and 1.293, respectively; CAT-related genes (LOC104905646) was regulated by upregulated expression between the two groups, and the gene expression levels were 0.388 and 0.885 . 


\subsection{Response of transcription factor-related genes to boron deficiency}

The study found that candidate genes related to transcription factor families, such as bHLH, WRKY, bZIP, MYB and B3 were differentially regulated between the two comparison groups (Fig.10), transcription factor-related candidate genes showed an up-regulated expression trend in $\mathrm{H}$ variety. For example, transcription factor bHLH01-like (LOC104889601) and transcription factor bHLH18-like (LOC104897819) were highly up-regulated in the HB0.1 vs HB50 comparison group, and the relative expression levels were 2.270 and 2.277, respectively. Probable WRKY transcriptionfactor 71 (LOC104883655) and probable disease resistance protein RF9 showed an up-regulated expression trend in the two comparison groups, with the highest gene relative expression levels being 2.422. Compared with the LB0.1 vs LB50 comparison group, transcription factors bZIP (LOC104887665, LOC104888761 and LOC104888878), MYB (LOC104890147, LOC104895749 and LOC104904231) and B3 (LOC104888813, LOC104889189, LOC104892359) were significantly upregulated and regulated in HB0.1 vs HB50 comparison group, while related candidate genes were not significantly different and expressed in $L$ variety. The lowest amount was -0.560 (LOC104888878), followed by LOC104887665. The relative expression of the candidate gene of B3 transcription factor cytosolic sulfotransferase 15 (LOC104888813) was3.714.

\subsection{Response of candidate genes related to aquaporin and boron transporter to boron deficiency}

The results showed that the candidate genes of aquaporin in sugar beet were differentially induced and regulated (Fig. 11). Aquaporin gene NIP5-1 (LOC104895986 and LOC104895985) were highly upregulated in the two comparison groups. Compared with B deficiency treatment, the gene expression levels were 1.980 and 1.099 , respectively, while LOC104893298 was highly downregulated in both groups Regulated, the expression levels are -5.072 and -1.161 . Aquaporin gene NIP6-1 (LOC104904889), boron transporter BOR2 (LOC104894816) and boron transporter 4 were up-regulated in the two varieties, and NIP7-1 (LOC104906876) was down-regulated in the two comparison groups. Compared with boron deficiency treatment, the gene expression level was -1.767 and -0.035 . Probable boron transporter 7 (LOC104887698) was highly down-regulated in the H variety, and the gene expression level was -2.544 .

\subsection{0 qRT-PCR validates transcriptome data}

In order to verify the accuracy and reproducibility of the Illumina RNA-seq results, 14 representative genes such as those involved in cell wall synthesis, POD enzymes, carbon and nitrogen metabolism and other related genes were selected to verify these by real-time quantitative PCR (qRT-PCR). The relative expression level of the selected gene was further compared with the relative expression from RNA-seq analysis. Although the results of qRT-PCR were not exactly the same as the results of RNA-seq, the qRTPCR results showed that the relative gene expression trends were consistent with the RNA-seq data, which verified the accuracy of the transcriptome sequencing results, thus supporting the reliability of the RNAseq results in this study. 


\section{Discussion}

\subsection{Boron efficient variety can alleviate the symptoms of boron deficiency on roots}

Boron is one of the micronutrient elements necessary for the growth and development of higher plants (Wu et al., 2017). The plants suffering from boron deficiency can cause the reduction of primary root length (Shah et al., 2017), an increase of root hair length and the number (González et al., 2008), which can lead to root growth inhibition in severe cases (Poza et al., 2018), due to the rapid inhibition of root cell elongation (Camacho et al., 2015). Root length ratio (RLR), root fineness (RF), and root mass ratio (RMR), root tissue density (RTD) are important characteristic indicators for evaluating root growth (Poza et al., 2018). Consistent with the law described above, in this study, boron deficiency reduced the total root length, root volume and root forks of sugar beet. Moreover, boron deficiency significantly reduced the biomass of sugar beet, such as root fresh weight and root dry weight (Fig. 2A; Fig. 2C). Further analysis of the root morphology and growth indicators of sugar beet showed that boron deficiency significantly reduced the root fineness (RFs) of $\mathrm{H}$ variety (52\%) and L variety (46\%) (Fig. S2B). Boron deficiency also reduced root length ratio $(28 \%)$, root mass ratio $(12 \%)$, specific root length $(21 \%)$ and specific surface area $(0.1 \%)$, but the reduction of $\mathrm{H}$ variety was less than that of $\mathrm{L}$ variety (Fig. S2), indicating that $\mathrm{H}$ variety had a higher tolerance to boron deficiency, it can accumulate more biomass under stress conditions and maintain the normal growth of plants.

\subsection{Boron efficient variety adapts to boron stress by activating the antioxidant enzyme system, relieving oxidative damage of roots}

Plant defense systems play an important role in oxidative damage caused by excessive accumulation of reactive oxygen species (Riaz et al., 2019). There is always a balance between the reactive oxygen species produced in plant metabolism and antioxidant enzymes (Hussain et al., 2016; Yan et al., 2018a, b). Salt stress treatment significantly increased POD and CAT enzyme activities in sugar beet roots (Liu et al., 2020). The large accumulation of reactive oxygen species (ROS) may cause oxidative stress in plants, eventually leading to oxidative damage to plants and even root damage (Riaz et al., 2018), which may be directly related to the inhibition of plant root elongation. Consistent with the above research results, compared with the $\mathrm{L}$ variety, the $\mathrm{H}$ variety showed higher tolerance to boron deficiency treatment, which was manifested in the significant increase of the POD and CAT enzyme activities in the root system under the boron deficiency (Fig. 3B, 3C). Regardless of the treatment, MDA content was reduced in the root system (Fig. 3D). In addition, through enrichment analysis of DEGs, it was found that $\mathrm{H}$ variety maintained the regularity and order in the roots of $\mathrm{H}$ variety by regulating the up-regulated expression of antioxidant enzyme-related genes such as SOD (LOC104899994), POD (LOC104908142) and CAT (LOC104905646) candidate genes (Fig. 9). Boron efficient variety reduced the MDA content and ROS 
accumulation in roots by regulating the synergy between antioxidant enzyme systems (Fig. 4), assisting plants in resisting stress and reducing plant oxidative damage.

\subsection{Boron efficient sugar beet variety promotes the efficient absorption and transport of boron by inducing the expression of aquaporins and boron transporters}

Plants control the absorption and transport of boron by regulating two different types of boron transporters, namely the borate channel of the main intrinsic protein family and the borate transporter of the BOR family (Yoshinari, 2017). Studies have proposed that NIP7;1 serves as a gated boric acid channel in developing anthers that aids in the uptake of this critical micronutrient by tapetal cells (Routray, 2018). Under B restriction conditions, BOR2 can transport boric acid/borates in roots from symplasts to apoplasts, and helps RG-Il to effectively cross-link in the cell wall and promote root cell elongation (Miwa, 2013). Under high boron treatment, plants can reduce the $B$ concentration in roots through BOR4 mediated B efflux, maintain plant boron steady state, and increase plant tolerance to high boron environment (Miwa, 2011). In our research results, NIP7-1 (LOC104906876) and BOR7 (LOC104887698) showed a downward-regulated expression trend in the H variety, while BOR2 (LOC104894816) and BOR4 (LOC104904614) showed an up-regulated expression trend in the $\mathrm{H}$ variety, indicating that the $\mathrm{H}$ variety may It also regulates the expression of the above genes, reduces the efflux of boron, and promotes the elongation of plant roots.

At low boron concentrations, plants induced the expression of NIP5-1 to complete the initial boron uptake (Takano et al., 2006) and promoted efficient boron absorption and boron nutrient accumulation by roots (Wang et al., 2017). BOR1 was the first boron transporter to be identified (Miwa, 2006), and it is mainly involved in the loading process of xylem in roots under low boron conditions (Larson, 2019). In this study, the relative expression levels of aquaporin and boron transfer genes in sugar beet roots were analyzed by gene fluorescence quantitative PCR, and it was found that the expression of NIP5-1 (LOC104895985, LOC104895986), NIP6-1 (LOC104904889), and BOR2 (LOC104894816) were up-regulated in H variety, and the relative expression of genes was higher than that in L cultivars (Fig. S3). Compared with the L variety, the $\mathrm{H}$ variety also had higher boron absorption and transfer capacity (Fig. 5C; Fig. 5D), so it can accumulate more boron for the plant under boron deficiency, and alleviate the boron deficiency symptoms of the plant.

\subsection{Signal transduction network involved in gene regulation under boron deficiency}

At present, studies on changes in the transcription level after B deficiency (Camacho-CristóBal et al., 2011; Liu et al., 2017) or related signal mechanism responses (Kasajima et al., 2010) have been carried out on Arabidopsis and Citrus. The research provided strong evidence for a clear elucidation of the molecular mechanism of boron deficiency. Boron deficiency can affect the expression of many TFs in plants, such 
as MYBs (Mun et al., 2017), WRKYs (Tripathi, 2014), bZIP (Shaikhali et al., 2012) and bHLHs (Fagerstedt et al., 2010). The plant-specific B3 family has special significance in regulating plant development, multiple pathways of defense response, and hormone-related signal transduction pathways (Sasnauskas et al., 2018; Verma, 2019). Similarly, WRKY and bHLH family transcription factors are also used to adapt to biological and abiotic stress responses and regulate stress response signals and ROS production (Yan et al., 2014; Sun, 2018). WRKY6 is a transcription factor induced by low B, which is essential for normal root growth under low B (Kasajima et al., 2010). Studies have found that WRKY33 and bHLH123 can regulate the expression of ROS scavenging oxidative stress response genes, and play an important role in scavenging ROS (Jiang, 2009), thereby improving plant resistance to stress (Zhao et al., 2018). In addition, bHLH2 also plays an active role in regulating stress (Yao et al., 2018). In our study, MYB family transcription factor PHL8 (LOC104897898), WRKY transcription factor 20 (LOC104891818) and transcription factor bHLH3 (LOC104894625) were up-regulated in the two comparison groups. Transcription factor bHLH14-like (LOC104892626) and bHLH3 (LOC104894625) was especially upregulated in $\mathrm{H}$ variety, and the expression level of genes was 1.158 and 0.347 respectively. In short, boron efficient sugar beet variety specifically up-regulated the expression of transcription factor-related genes such as B3, bHLH and bZIP (Fig. 9), activating the plant defense system, regulating the normal growth and development of plants.

Auxin signal transduction determines the structure of root tip cells (Muraro et al., 2013). Studies have found that there is a potential interaction between boron and hormones such as indoleacetic acid (IAA) and abscisic acid (ABA) (Matthes et al., 2020). The expression of AtNIP5-1 was controlled by hormones (Gómez-soto et al., 2019). The correlation between ABA-induced AtNIP5-1 expression and boron uptake was speculated to be an early boron stress response (Macho-Rivero et al., 2017). Under boron deficiency, both ABA and its glycosyl esters in rape increased (Eggert and von Wirén, 2017). Studies have shown that ABA is a key hormone related to plant response to abiotic stress (Fujii and Zhu, 2009), and may inhibit root growth by inducing excessive production of ROS (Finkelstein et al., 2002; Geng et al., 2013), and interact with auxin to regulate auxin transport or signal transduction (Wang et al., 2011; Zhao et al., 2015a).

In addition, through the construction of efficient physiological and molecular patterns of boron efficient genotypes (Fig. 13), further analysis and comparison of the root morphology of different boron-efficient beet varieties confirmed these conjectures and inferences, overall, under the induction of boron deficiency, the boron-efficient variety activated the physiological defense response, maintained the regular antioxidant enzyme system, reduced the MDA content and the accumulation of active oxygen in the root system, and reduced the oxidative damage of the plant. In a word, boron-efficient varieties also upregulated the expression of related candidate genes such as TFs, transporters and hormones to establish a molecular interaction network system for efficient boron absorption and utilization to alleviate the symptoms of plant deficiency.

\section{Conclusions}


The results showed that boron deficiency can inhibit root elongation and reduce root-to-shoot ratio and root fork, thereby affecting the normal growth of roots. Boron deficiency significantly reduced the accumulation of root biomass and boron nutrition. Compared with normal boron treatment, boron deficiency significantly increased the POD and CAT enzyme activities of $\mathrm{H}$ variety, thereby reducing the oxidative damage of $\mathrm{H}$ variety. The $\mathrm{H}$ variety also has a strong boron utilization ability, and can accumulate more boron nutrition under the condition of boron deficiency. At the same time, this study also showed that efficient boron variety have complex transcriptional molecular network changes that regulate the up-regulation of antioxidant activity, peroxide and oxidoreductase activity and other related $\mathrm{GO}$ terms. Secondly, the $\mathrm{H}$ variety also regulated the expression of antioxidant enzymes, hormones, transcription factors and other boron deficiency-responsive genes. In short, the efficient B variety enhanced the plant's antioxidant capacity by regulating the expression of boron deficiency response genes, improved the boron utilization efficiency, and alleviated the symptoms of boron deficiency in the root system.

\section{Abbreviations}

\begin{tabular}{|llll|}
\hline Full name & abbreviation & Full name & abbreviation \\
\hline Boron & B & Foldchange & \\
\hline Root-shoot ratio & RSR & Superoxide dismutase & SOD \\
\hline Total biomass & TB & Peroxidase & POD \\
\hline Total root length & TRL & Catalase & CAT \\
\hline Root average diameter & RAD & Specific root length & SRL \\
\hline Root volume & RV & Specific root area & SRA \\
\hline Root forks & RFs & Dry weight & DW \\
\hline Malondialdehyde content & MDA & Fresh weight & FW \\
\hline Differentially expressed genes & DEGs & Root tissue density & RTD \\
\hline Molecular function & MF & Total surface area & TSA \\
\hline Cellular component & CC & Root length ratio & RLR \\
\hline Biological process & BP & Root fineness & RF \\
\hline RNA sequencing & RNA-Seq & Root mass ratio & RMR \\
\hline
\end{tabular}

\section{References}

1. Song, B., Hao, X., Wang, X., et al., 2019. Boron stress inhibits beet (Beta vulgaris L.) growth through influencing endogenous hormones and oxidative stress response. Soil Science and Plant Nutrition, 
65(7), 346-352.https://doi.org/10.1080/00380768.2019.1617641

2. Porcel, R., Bustamante, A., Ros, R., et al., 2018. BvCOLD1: A novel aquaporin from sugar beet (Beta vulgaris L.) involved in boron homeostasis and abiotic stress. Plant, cell \& environment, 41(12), 2844-2857. https://doi.org/10.1111/pce.13416

3. Evans, E., Messerschmidt, U. 2017. Review: Sugar beets as a substitute for grain for lactating dairy cattle. Journal of animal science and biotechnology, 8, 25. https://doi.org/10.1186/s40104-0170154-8

4. Zabed, H., Faruq, G., Sahu, J. N., et al., 2014. Bioethanol production from fermentable sugar juice. The Scientific World Journal, 2014, 957102.https://doi.org/10.1155/2014/957102

5. Magaña, C., Núñez-Sánchez, N., Fernández-Cabanás, V. M., et al., 2011. Direct prediction of bioethanol yield in sugar beet pulp using near infrared spectroscopy. Bioresource technology, 102(20), 9542-9549.http://doi.org/10.1016/j.biortech.2011.07.045

6. Warington, K. 1923. The effect of boric acid and borax on the broad bean and certain other plants. Ann. Bot.37, 629-672.http://dio.org10.1093/oxfordjournals.aob.a089871

7. Nable, R.O., Banuelos, G.S., Paull, J.G. 1997. B toxicity. Plant Soil, 193: 181198. http://dio.org/10.1023/A:1004272227886

8. Sillanpaa, M. 1990. Micronutrient assessment at the country level: An international study. InFao Soils Bulletin;Celko, J., Ed.; FAO: Rome, Italy , pp. 119-128.

9. Shireen, F., Nawaz, M. A., Chen, C., et al., 2018. Boron: Functions and Approaches to Enhance Its Availability in Plants for Sustainable Agriculture. International journal of molecular sciences, 19(7), 1856. https://doi.org/10.3390/ijms19071856

10. Blevins, D. G., Lukaszewski, K. M. 1998. Boron in plant structure and function. Annual review of plant physiology and plant molecular biology, 49, 481-500.

http://doi.org/10.1146/annurev.arplant.49.1.481

11. Schachtman, D. P., Goodger, J. Q. 2008. Chemical root to shoot signaling under drought. Trends in plant science, 13(6), 281-287.https://doi.org/10.1016/j.tplants.2008.04.003

12. Hu, L., Xie, Y., Fan, S., et al., 2018. Comparative analysis of root transcriptome profiles between drought-tolerant and susceptible wheat genotypes in response to water stress. Plant science: an international journal of experimental plant biology, 272, 276-293.

https://doi.org/10.1016/j.plantsci.2018.03.036

13. Zhang, C., Zhang, L., Zhang, S., et al., 2015. Global analysis of gene expression profiles in physic nut (Jatropha curcas L.) seedlings exposed to drought stress. BMC plant biology, 15, 17. https://doi.org/10.1186/s12870-014-0397-x

14. Camacho-Cristóbal JJ, Rexach J, González-Fontes A. 2008. Boron in plants: deficiency and toxicity. J Integr Plant Biol, 50: 1247-1255.http://dio.org10.1111/j.1744-7909.2008.00742.x

15. González-Fontes, A., Rexach, J., Navarro-Gochicoa, M.T., et al., 2008. Is boron involved solely in structural roles in vascular plants? Plant Signal. Behav. 3, 24-26.http://doi.org10.4161/psb.3.1.4812 
16. Pang, J.Y., Ryan, M.H., Tibbett, M., et al., 2010. Variation in morphological and physiological parameters in herbaceous perennial legumes in response to phosphorus supply. Plant Soil 331, 241255. http://doi.org/10.1007/s11104-009-0249-x

17. Doblin, M.S., Pettolino, F., Bacic, A., 2010. Plant cell walls: the skeleton of the plant world. Funct. Plant Biol. 37, 357-381.http://doi.org10.1071/FP09279

18. Huang, Y., Wang, S., Shi, L., et al., 2021. JAR1 negatively regulates root growth under boron deficiency in Arabidopsis. Journal of experimental botany, erab041. Advance online publication. https://doi.org/10.1093/jxb/erab041

19. Poza-Viejo, L., Abreu, I., González-García, M. P., et al., 2018. Boron deficiency inhibits root growth by controlling meristem activity under cytokinin regulation. Plant science: an international journal of experimental plant biology, 270, 176-189. https://doi.org/10.1016/j.plantsci.2018.02.005

20. Raven, J.A. 1980. Short- and long-distance transport of boric acid in plants. New Phytologist 84, 231249. https://doi.org/10.1111/j.1469-8137.1980.tb04424.x

21. Dordas, C., Brown, P. H. 2000. Permeability of boric acid across lipid bilayers and factors affecting it. The Journal of membrane biology, 175(2), 95-105. http://doi.org/10.1007/s002320001058

22. Roberts D.M., Routray P. 2017. The Nodulin 26 Intrinsic Protein Subfamily. In: Chaumont F., Tyerman S. (eds) Plant Aquaporins. Signaling and Communication in Plants. Springer, Cham. https://doi.org/10.1007/978-3-319-49395-4_13

23. Granado-Rodríguez, S., Bolaños, L., Reguera, M. 2020. MtNIP5;1, a novel Medicago truncatula boron diffusion facilitator induced under deficiency. BMC plant biology, 20(1), 552. https://doi.org/10.1186/s12870-020-02750-4

24. Brown, P. H., Bellaloui, N., Wimmer, M. A., et al. 2002. Boron in plant biology.Plant Biol.4, 205223.http://doi.org/10.1055/s-2002-25740

25. Reid, R. 2014. Understanding the boron transport network in plants. Plant Soil 385, 113.http://doi.org/10.1007/s11104-014-2149-y

26. Imadi, S. R., Kazi, A. G., Ahanger, M. A., et al., 2015. Plant transcriptomics and responses to environmental stress: an overview. Journal of genetics, 94(3), 525-

537. https://doi.org/10.1007/s12041-015-0545-6

27. Mazzitelli, J. Y., Bonnafe, E., Klopp, C., et al., 2017. De novo transcriptome sequencing and analysis of freshwater snail (Radix balthica) to discover genes and pathways affected by exposure to oxazepam. Ecotoxicology (London, England), 26(1), 127-140. https://doi.org/10.1007/s10646-0161748-1

28. Jiang, W., Wu, Z., Wang, T., et al., 2020. Physiological and transcriptomic analyses of cadmium stress response in Dendrobium officinale seedling. Plant physiology and biochemistry: PPB, 148, 152-165. https://doi.org/10.1016/j.plaphy.2020.01.010

29. Dohm, J. C., Minoche, A. E., Holtgräwe, D., et al., 2014. The genome of the recently domesticated crop plant sugar beet (Beta vulgaris). Nature, 505(7484), 546-549. http://doi.org/10.1038/nature12817 
30. Yu, B., Chen, M., Grin, I., et al., 2020. Mechanisms of Sugar Beet Response to Biotic and Abiotic Stresses. Advances in experimental medicine and biology, 1241, 167-

194. https://doi.org/10.1007/978-3-030-41283-8_10

31. Liu, L., Wang, B., Liu, D., et al., 2020. Transcriptomic and metabolomic analyses reveal mechanisms of adaptation to salinity in which carbon and nitrogen metabolism is altered in sugar beet roots. BMC plant biology, 20(1), 138.https://doi.org/10.1186/s12870-020-02349-9

32. Lv, X., Jin, Y., Wang, Y. 2018. De novo transcriptome assembly and identification of salt-responsive genes in sugar beet M14. Computational biology and chemistry, 75, 1-10. https://doi.org/10.1016/j.compbiolchem.2018.04.014

33. Kito, K., Tsutsumi, K., Rai, V., et al., 2017. Isolation and functional characterization of 3phosphoglycerate dehydrogenase involved in salt responses in sugar beet. Protoplasma, 254(6), 2305-2313. https://doi.org/10.1007/s00709-017-1127-7

34. Hossain, M. S., ElSayed, A. I., Moore, M., et al., 2017. Redox and Reactive Oxygen Species Network in Acclimation for Salinity Tolerance in Sugar Beet. Journal of experimental botany, 68(5), 12831298. https://doi.org/10.1093/jxb/erx019

35. Moliterni, V. M., Paris, R., Onofri, C., et al., 2015. Early transcriptional changes in Beta vulgaris in response to low temperature. Planta, 242(1), 187-201.https://doi.org/10.1007/s00425-015-2299-z

36. Guo, J., Li, C., Zhang, X., et al., 2020. Transcriptome and GWAS analyses reveal candidate gene for seminal root length of maize seedlings under drought stress. Plant science: an international journal of experimental plant biology, 292, 110380. https://doi.org/10.1016/j.plantsci.2019.110380

37. Amirbakhtiar, N., Ismaili, A., Ghaffari, M. R., et al., 2019. Transcriptome response of roots to salt stress in a salinity-tolerant bread wheat cultivar. PloS one, 14(3), e0213305. https://doi.org/10.1371/journal.pone.0213305

38. Hua, Y., Zhou, T., Ding, G., et al., 2016. Physiological, genomic and transcriptional diversity in responses to boron deficiency in rapeseed genotypes. Journal of experimental botany, 67(19), 57695784. https://doi.org/10.1093/jxb/erw342

39. Hoagland, DR., D. i. Arnon. 1950. The water culture method for growing plants without soil. Calif.agric.exp.stn.circ, 347(5406), 357-359. https://doi.org/10.1016/S0140-6736(00)73482-9

40. Ali, S., Xu, Y.Y., Ahmad, I. et al. 2018. Tillage and deficit irrigation strategies to improve winter wheat production through regulating root development under simulated rainfall conditions. Agric. Water Manag. 209, 44-54.https://doi.org/10.1016/j.agwat.2018.07.007

41. Beauchamp, C., Fridovich, I. 1971. Superoxide dismutase: improved assays and an assay applicable to acrylamide gels. Analytical biochemistry, 44(1), 276-287. https://doi.org/10.1016/00032697(71)90370-8

42. Cakmak, I., Horst, W.J., 1991. Effect of aluminium on lipid peroxidation, superoxide dismutase, catalase, and peroxidase activities in root tips of soybean (Glycine max). Physiol.Plantarum83, 463468. http://doi.org/10.1111/j.1399-3054.1991.tb00121.x 
43. De Azevedo Neto, A.D., Prisco, J.T., Enéas-Filho, J., et al., 2006. Effect of salt stress on antioxidative enzymes and lipid peroxidation in leaves and roots of salt-tolerant and salt-sensitive maize genotypes. Environ. Exp. Bot. 56(1), 87-94.http://doi.org/10.1016/j.envexpbot.2005.01.008

44. Vos $\mathrm{C}$, Schat $\mathrm{H}$, Waal M, et al., 1991. Increased resistance to copper-induced damage of the root cell plasmalemma in copper tolerant Silene cucubalus. Physiol Plant, 82: 523-

528. http://doi.org/10.1111/j.1399-3054.1991.tb02942.x

45. Dible, W. T., Truog, E., Berger, K. C. 1954. Boron Determination in Soils and Plants. Analytical Chemistry. 26(2), 186-196. https://doi.org/10.1021/ac60086a047

46. Young, M. D., Wakefield, M. J., et al., 2010. Gene ontology analysis for RNA-seq: accounting for selection bias. Genome biology, 11(2), R14.https://doi.org/10.1186/gb-2010-11-2-r14

47. Thimm, O., Bläsing, O., Gibon, Y., et al., 2004. MAPMAN: a user-driven tool to display genomics data sets onto diagrams of metabolic pathways and other biological processes. The Plant journal: for cell and molecular biology, 37(6), 914-939. https://doi.org/10.1111/j.1365-313x.2004.02016.x

48. Rao, X., Huang, X., Zhou, Z., et al., 2013. An improvement of the $2^{\wedge}$ (-delta delta CT) method for quantitative real-time polymerase chain reaction data analysis. Biostatistics, bioinformatics and biomathematics, 3(3), 71-85.http://doi.org/10.1016/S0920-5489(99)92176-1

49. Wu, X., Riaz, M., Yan, L., et al., 2017. Boron Deficiency in Trifoliate Orange Induces Changes in Pectin Composition and Architecture of Components in Root Cell Walls. Frontiers in plant science, 8, 1882. https://doi.org/10.3389/fpls.2017.01882

50. Shah, A., Wu, X., Ullah, A., et al., 2017. Deficiency and toxicity of boron: Alterations in growth, oxidative damage and uptake by citrange orange plants. Ecotoxicology and environmental safety, 145, 575-582.https://doi.org/10.1016/j.ecoenv.2017.08.003

51. Poza-Viejo, L., Abreu, I., González-García, M. P., et al., 2018. Boron deficiency inhibits root growth by controlling meristem activity under cytokinin regulation. Plant science: an international journal of experimental plant biology, 270, 176-189.https://doi.org/10.1016/j.plantsci.2018.02.005

52. Camacho-Cristóbal, J. J., Martín-Rejano, E. M., Herrera-Rodríguez, M. B., et al., 2015. Boron deficiency inhibits root cell elongation via an ethylene/auxin/ROS-dependent athway in Arabidopsis seedlings. J. Exp. Bot.66, 3831-3840.https://doi.org/10.1093/jxb/erv186

53. Riaz, M., Yan, L., Wu, X., et al., 2019. Boron supply maintains efficient antioxidant system, cell wall components and reduces aluminum concentration in roots of trifoliate orange. Plant physiology and biochemistry: PPB, 137, 93-101.https://doi.org/10.1016/j.plaphy.2019.02.003

54. Hussain, S., Khan, F., Cao, W., et al., 2016. Seed Priming Alters the Production and Detoxification of Reactive Oxygen Intermediates in Rice Seedlings Grown under Sub-optimal Temperature and Nutrient Supply. Frontiers in plant science, 7, 439. https://doi.org/10.3389/fpls.2016.00439

55. Yan, L., Riaz, M., Wu, X., et al., 2018a. Interaction of boron and aluminum on the physiological characteristics of rape (Brassica napus L.) seedlings. Acta Physiol. Plant. 40, 33. https://doiorg/10.1007/s11738-018-2614-y 
56. Yan, L., Riaz, M., Wu, X., et al., 2018. Boron inhibits aluminum-induced toxicity to citrus by stimulating antioxidant enzyme activity. Journal of environmental science and health. Part C, Environmental carcinogenesis \& ecotoxicology reviews, 36(3), 145-163.

https://doi.org/10.1080/10590501.2018.1490513

57. Liu, L., Wang, B., Liu, D., et al., 2020. Transcriptomic and metabolomic analyses reveal mechanisms of adaptation to salinity in which carbon and nitrogen metabolism is altered in sugar beet roots. BMC plant biology, 20(1), 138.https://doi.org/10.1186/s12870-020-02349-9

58. Riaz, M., Yan, L., Wu, X., et al., 2018a.Boron reduces aluminum-induced growth inhibition, oxidative damage and alterations in the cell wall components in the roots of trifoliate orange. Ecotoxicol. Environ. Saf. 153, 107-115. https://doi.org/10.1016/j.ecoenv.2018.02.002

59. Yoshinari, A., Takano, J. 2017. Insights into the Mechanisms Underlying Boron Homeostasis in Plants. Frontiers in plant science, 8, 1951.https://doi.org/10.3389/fpls.2017.01951

60. Routray, P., Tian, L., Yamasaki, A., et al., 2018. Nodulin intrinsic protein 7;1 is a tapetal boric acid channel involved in pollen cell wall formation. Plant Physiology, 178(3), pp.00604.2018. https//:doi.org/10.1104/pp.18.00604

61. Miwa, K., Wakuta, S., Takada, S., et al., 2013. Roles of bor2, a boron exporter, in cross linking of rhamnogalacturonan ii and root elongation under boron limitation in arabidopsis. Plant Physiology, 163(4), 1699-1709. https//:doi.org/10.1104/pp.113.225995

62. Miwa, K., Fujiwara, T., 2011. Role of overexpressed bor4, a boron exporter, in tolerance to high level of boron in shoots. Soil Science and Plant Nutrition, 57(4), 558-565.

https//:doi.org/10.1080/00380768.2011.596473

63. Takano, J., Wada, M., Ludewig, U., et al., 2006. The Arabidopsis major intrinsic protein NIP5;1 is essential for efficient boron uptake and plant development under boron limitation. The Plant cell, 18(6), 1498-1509.https://doi.org/10.1105/tpc.106.041640

64. Wang, S., Yoshinari, A., Shimada, T., et al., 2017. Polar Localization of the NIP5;1 Boric Acid Channel Is Maintained by Endocytosis and Facilitates Boron Transport in Arabidopsis Roots. The Plant cell, 29(4), 824-842.https://doi.org/10.1105/tpc. 16.00825

65. Miwa, K., Takano, J., Fujiwara, T. 2006. Improvement of seed yields under boron-limiting conditions through overexpression of BOR1, a boron transporter for xylem loading, in Arabidopsis thaliana. The Plant journal : for cell and molecular biology, 46(6), 1084-1091. https://doi.org/10.1111/j.1365313X.2006.02763.X

66. Larson E. R. 2019. Two Pathways for Trafficking the Borate Receptor BOR1. Plant physiology, 179(4), 1437-1438. https://doi.org/10.1104/pp.19.00180

67. Camacho-Cristóbal, J.J., Rexach, J., Herrera-Rodríguez, M.B., et al., 2011. Boron deficiency and transcript level changes. PlantSci. 181, 85-89.http://doi.org/10.1016/j.plantsci.2011.05.001

68. Liu, X., Zhang, J. W., Guo, L. X., et al., 2017. Transcriptome changes associated with boron deficiency in leaves of two citrus scion-rootstock combinations. Frontiers in plant science, 8, 317. https://doi.org/10.3389/fpls.2017.00317 
69. Kasajima, I., Ide, Y., Yokota Hirai, M., et al., 2010. WRKY6 is involved in the response to boron deficiency in Arabidopsis thaliana. Physiol. Plant 139, 80-92.

http://doi.org/10.1016/j.plantsci.2011.05.001

70. Mun, B. G., Lee, S. U., Park, E. J., et al., 2017. Analysis of transcription factors among differentially expressed genes induced by drought stress in Populus davidiana. 3 Biotech, 7(3), 209. https://doi.org/10.1007/s13205-017-0858-7

71. Tripathi, P., Rabara, R. C., Rushton, P. J. 2014. A systems biology perspective on the role of WRKY transcription factors in drought responses in plants. Planta, 239(2), 255-266. https://doi.org/10.1007/s00425-013-1985-y

72. Shaikhali, J., Norén, L., de Dios Barajas-López, J., et al., 2012. Redox-mediated mechanisms regulate DNA binding activity of the G-group of basic region leucine zipper (bZIP) transcription factors in Arabidopsis. The Journal of biological chemistry, 287(33), 27510-27525. https://doi.org/10.1074/jbc.M112.361394

73. Fagerstedt, K. V., Kukkola, E. M., Koistinen, V. V., et al., 2010. Cell wall lignin is polymerised by class III secretable plant peroxidases in Norway spruce. Journal of integrative plant biology, 52(2), 186-194. https://doi.org/10.1111/j.1744-7909.2010.00928.x

74. Sasnauskas, G., Manakova, E., Lapėnas, K., et al., 2018. DNA recognition by Arabidopsis transcription factors ABI3 and NGA1. The FEBS journal, 285(21), 4041-4059. https://doi.org/10.1111/febs.14649

75. Verma, S., Bhatia, S. 2019. A comprehensive analysis of the B3 superfamily identifies tissue-specific and stress-responsive genes in chickpea (Cicer arietinum L.). 3 Biotech, 9(9), 346. https://doi.org/10.1007/s13205-019-1875-5

76. Yan, H., Jia, H., Chen, X., et al., 2014. The cotton WRKY transcription factor GhWRKY17 functions in drought and salt stress in transgenic Nicotiana benthamiana through ABA signaling and the modulation of reactive oxygen species production. Plant \& cell physiology, 55(12), 2060-2076. https://doi.org/10.1093/pcp/pcu133

77. Sun, X., Wang, Y., Sui, N. 2018. Transcriptional regulation of bHLH during plant response to stress. Biochemical and biophysical research communications, 503(2), 397-401. https://doi.org/10.1016/j.bbrc.2018.07.123

78. Jiang, Y., Deyholos, M. K. 2009. Functional characterization of Arabidopsis NaCl-inducible WRKY25 and WRKY33 transcription factors in abiotic stresses. Plant molecular biology, 69(1-2), 91-105. https://doi.org/10.1007/s11103-008-9408-3

79. Zhao, Q., Xiang, X., Liu, D., et al., 2018. Tobacco Transcription Factor NtbHLH123 Confers Tolerance to Cold Stress by Regulating the NtCBF Pathway and Reactive Oxygen Species Homeostasis. Frontiers in plant science, 9, 381.https://doi.org/10.3389/fpls.2018.00381

80. Yao, P., Sun, Z., Li, C., et al., 2018. Overexpression of Fagopyrum tataricum FtbHLH2 enhances tolerance to cold stress in transgenic Arabidopsis. Plant physiology and biochemistry: PPB, 125, 8594. https://doi.org/10.1016/j.plaphy.2018.01.028 
81. Muraro, D., Byrne, H., King, J., et al., 2013. The role of auxin and cytokinin signalling in specifying the root architecture of Arabidopsis thaliana. Journal of theoretical biology, 317, 71-86. https://doi.org/10.1016/j.jtbi.2012.08.032

82. Matthes, M. S., Robil, J. M., McSteen, P, 2020. From element to development: the power of the essential micronutrient boron to shape morphological processes in plants. Journal of experimental botany, 71(5), 1681-1693. https://doi.org/10.1093/jxb/eraa042

83. Gómez-Soto, D., Galván, S., Rosales, E., et al., 2019. Insights into the role of phytohormones regulating pAtNIP5; 1 activity and boron transport in Arabidopsis thaliana. Plant science: an international journal of experimental plant biology, 287, 110198. https://doi.org/10.1016/j.plantsci.2019.110198

84. Macho-Rivero, M. Á., Camacho-Cristóbal, J. J., Herrera-Rodríguez, M. B., et al., 2017. Abscisic acid and transpiration rate are involved in the response to boron toxicity in Arabidopsis plants. Physiologia plantarum, 160(1), 21-32. https://doi.org/10.1111/ppl.12534

85. Eggert, K., von Wirén, N. 2017. Response of the plant hormone network to boron deficiency. The New phytologist, 216(3), 868-881. https://doi.org/10.1111/nph.14731

86. Fujii, H., Zhu, J. K. 2009. Arabidopsis mutant deficient in 3 abscisic acid-activated protein kinases reveals critical roles in growth, reproduction, and stress. Proceedings of the National Academy of Sciences of the United States of America, 106(20), 83808385. https://doi.org/10.1073/pnas.0903144106

87. Finkelstein, R. R., Gampala, S. S., Rock, C. D. 2002. Abscisic acid signaling in seeds and seedlings. The Plant cell, 14 Suppl(Suppl), S15-S45. https://doi.org/10.1105/tpc.010441

88. Geng, Y., Wu, R., Wee, C. W., et al., 2013. A spatio-temporal understanding of growth regulation during the salt stress response in Arabidopsis. The Plant cell, 25(6), 2132-2154. https://doi.org/10.1105/tpc.113.112896

89. Wang, L., Hua, D., He, J., et al., 2011. Auxin Response Factor2 (ARF2) and its regulated homeodomain gene HB33 mediate abscisic acid response in Arabidopsis. PLoS genetics, 7(7), e1002172. https://doi.org/10.1371/journal.pgen.1002172

90. Zhao, F. Y., Cai, F. X., Gao, H. J., et al., 2015. Aba plays essential roles in regulating root growth by interacting with auxin and mapk signaling pathways and cell-cycle machinery in rice seedlings. Plant Growth Regulation, 75(2), 535-547.https://doi.org/10.1007/s10725-014-0017-7

\section{Figures}




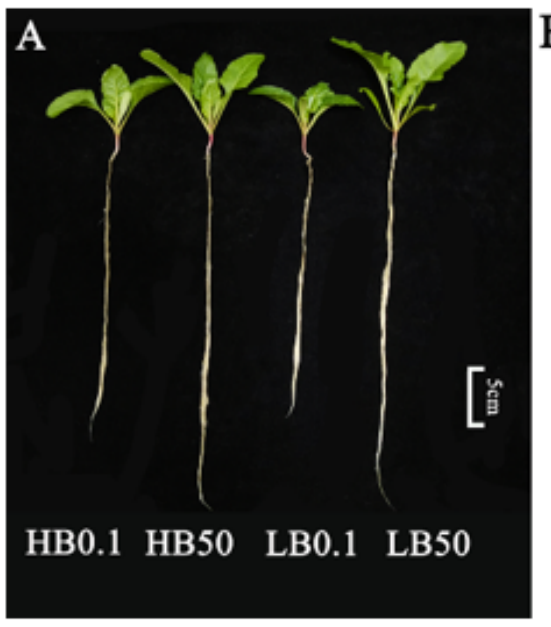

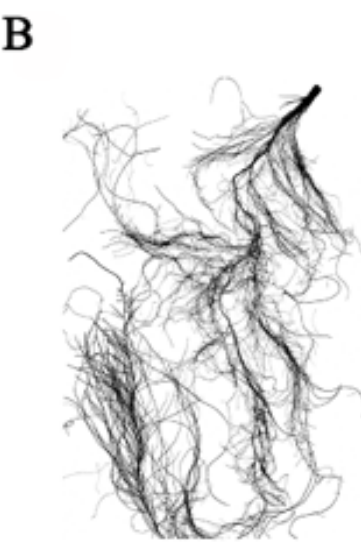

HB0.1

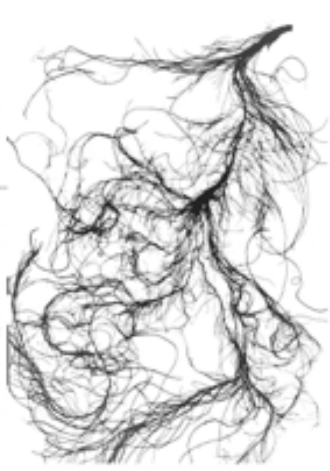

HB50

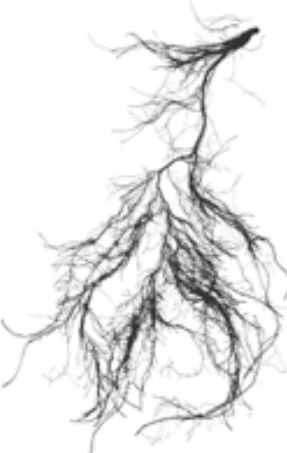

LB0.1

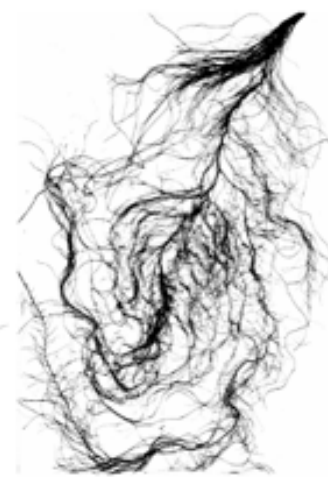

LB50
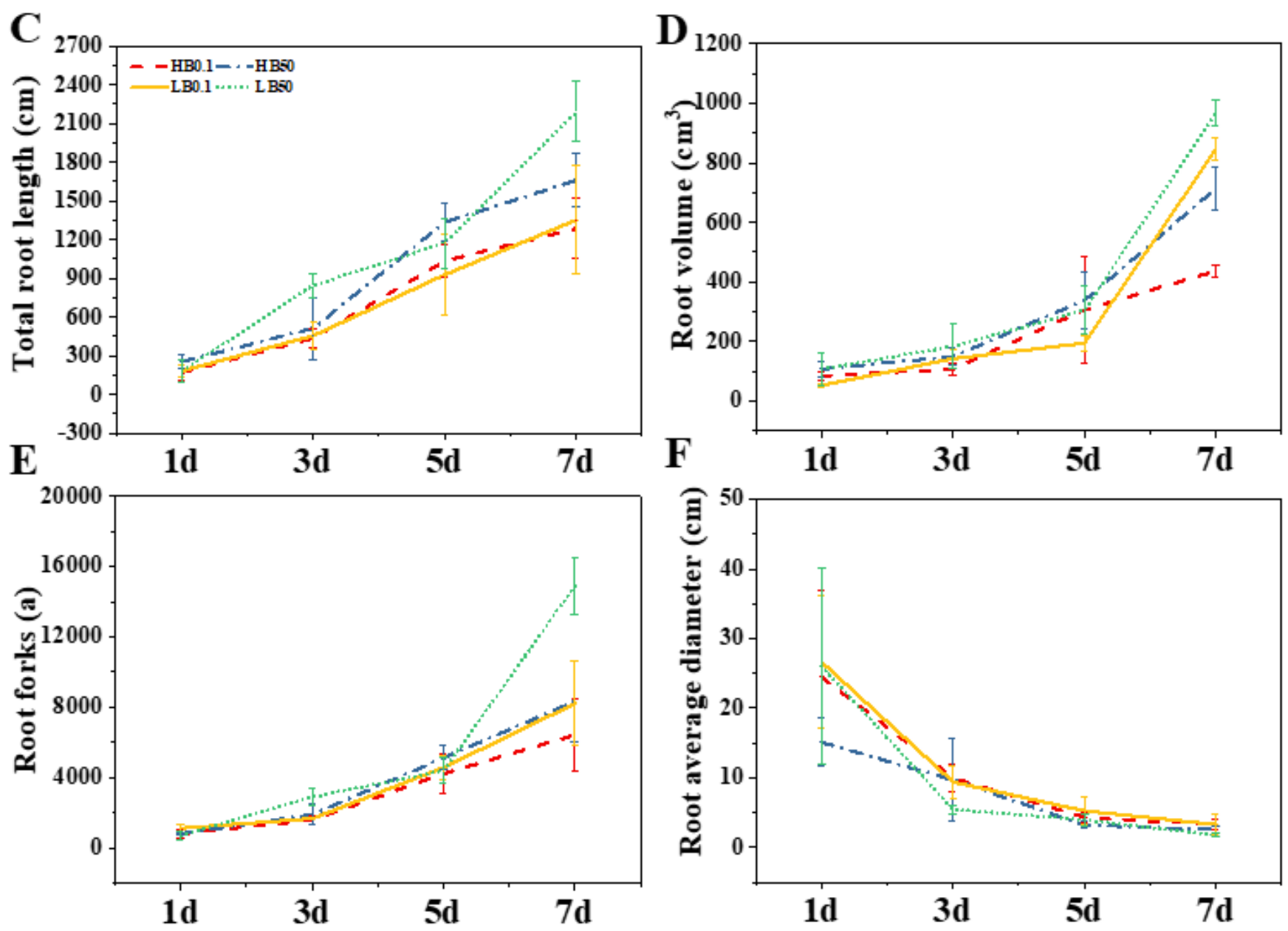

Figure 1

(A) The growth status of sugar beet plants under 7 days of boron treatment. (B) Root morphology of sugar beet after 7 days of boron deficiency. The seedlings of sugar beet under the stress of $1 d, 3 d, 5 d, 7 d$ of boron deficiency were harvested and divided into two parts: the shoot and the root system. The root system was used for root scanning experiment. Each treatment included 4 biological replicates. The 
effect of boron deficiency on (C) total root length (TRL); (D) root average diameter (RAD); (E) root volume (RV); (F) root forks (RF).
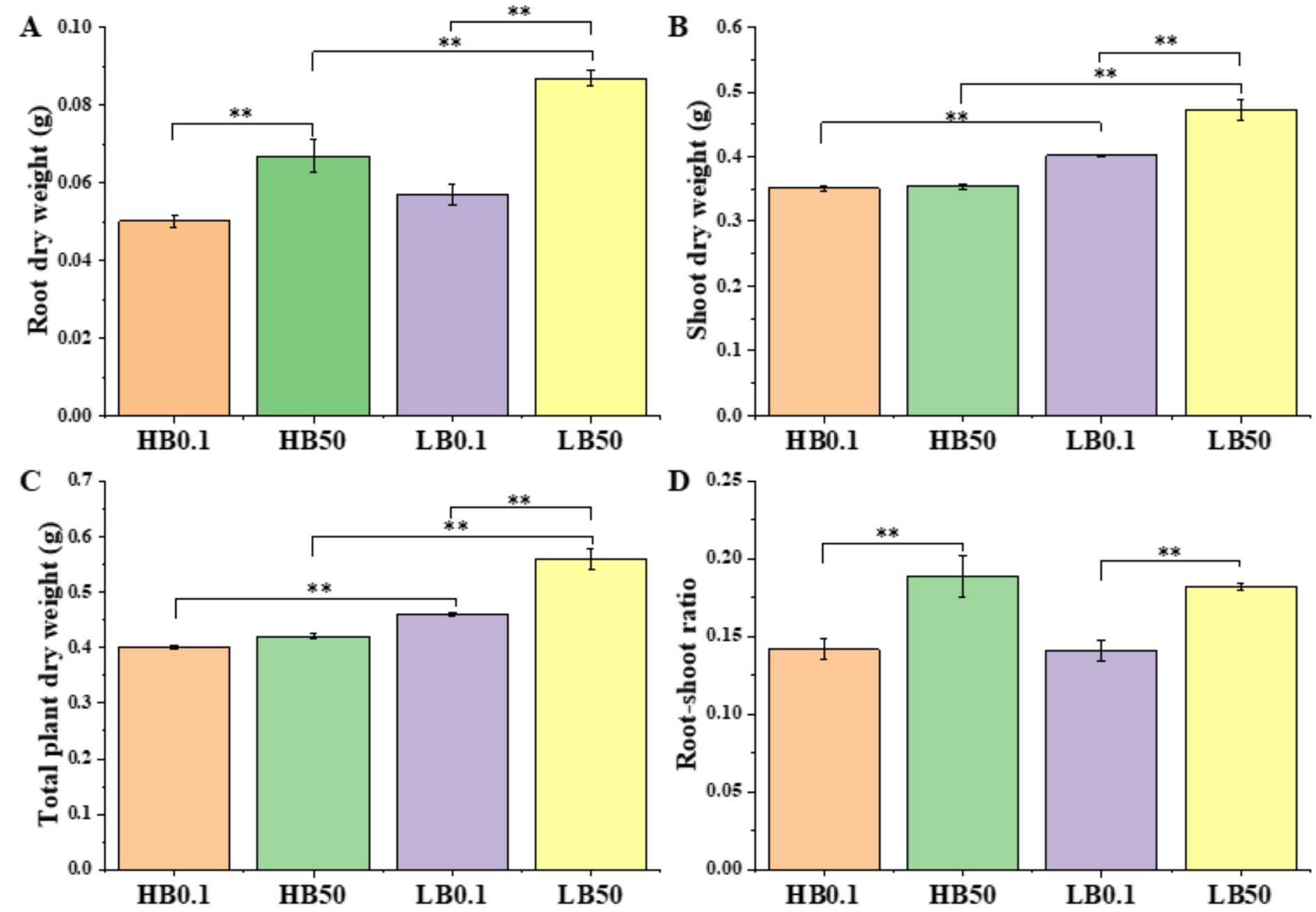

\section{Figure 2}

The effect of boron deficiency on (A) Root dry weight; (B) Shoot dry weight; (C) Total plant dry weights; (D) Root-shoot ratio. Error bars are represented by $\pm S D(n=3)$. Two-way ANOVA was used to analyze the significant differences between plants under different boron treatment, with " $*$ " indicating $p<0.05$, and "**" indicating $p<0.01$. 

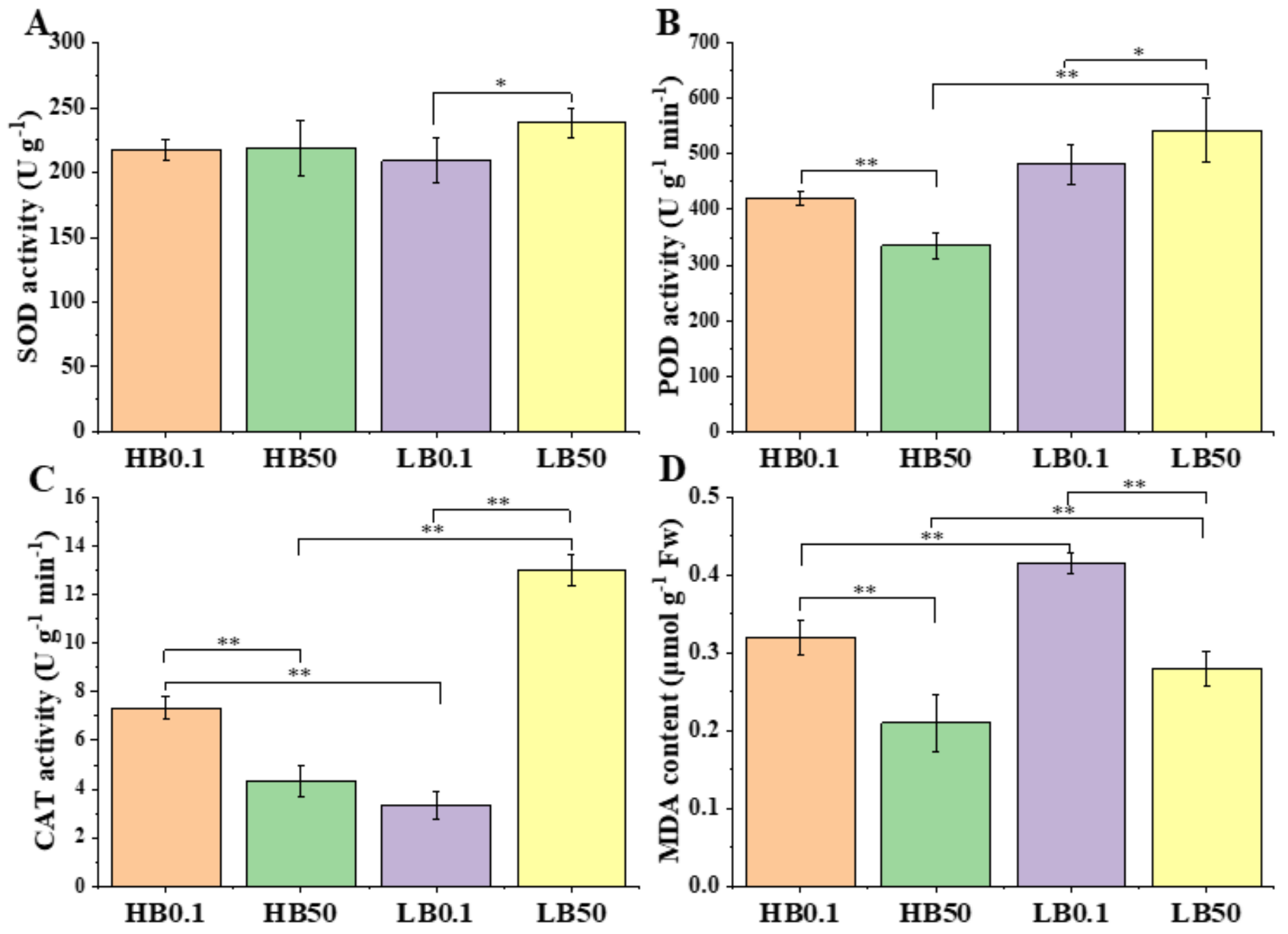

Figure 3

The effect of boron deficiency on (A) SOD activity; (B) POD activity; (C) CAT activity; (D) MDA content of the root system. Error bars are represented by $\pm S D(n=3)$. Two-way ANOVA was used to analyze the significant differences between plants under different B concentrations, with "*" indicating $p<0.05$, and "**" indicating $\mathrm{p}<0.01$. 


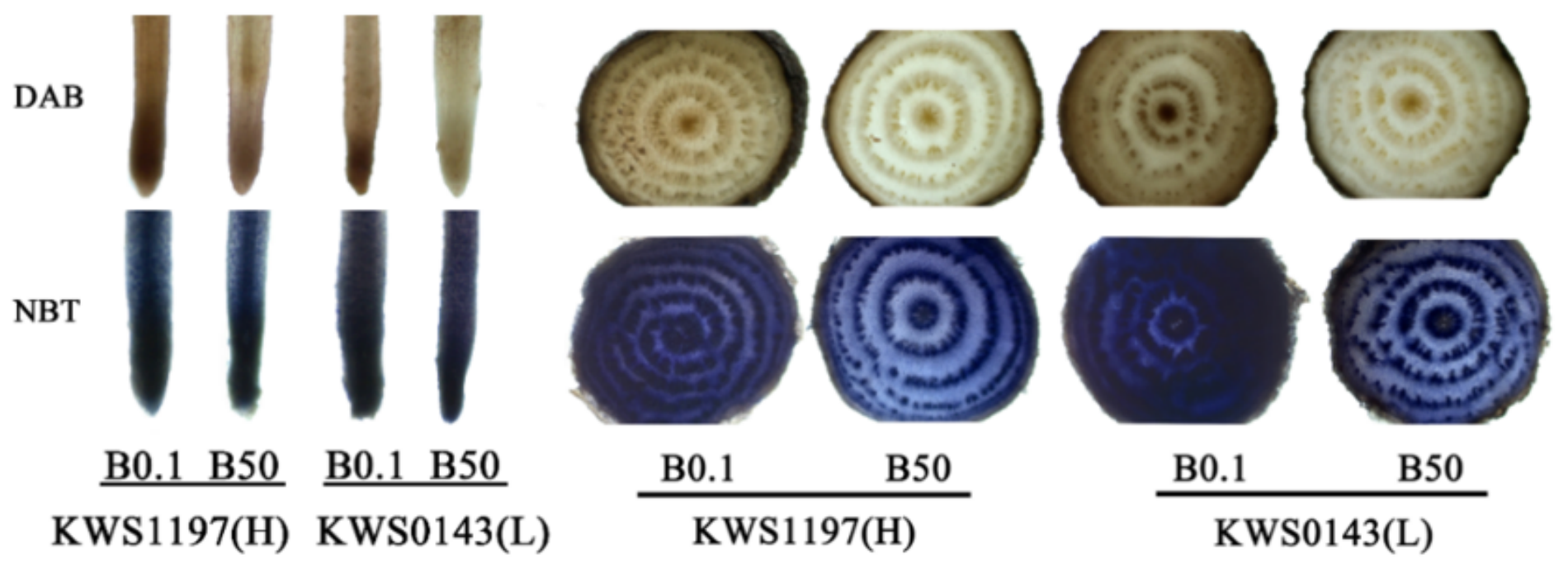

Figure 4

Histochemical staining of root system. The DAB staining in the figure indicated the accumulation of hydrogen peroxide ( $\mathrm{H} 2 \mathrm{O} 2)$, and the NBT staining indicated the accumulation of superoxide anions (02.-). 

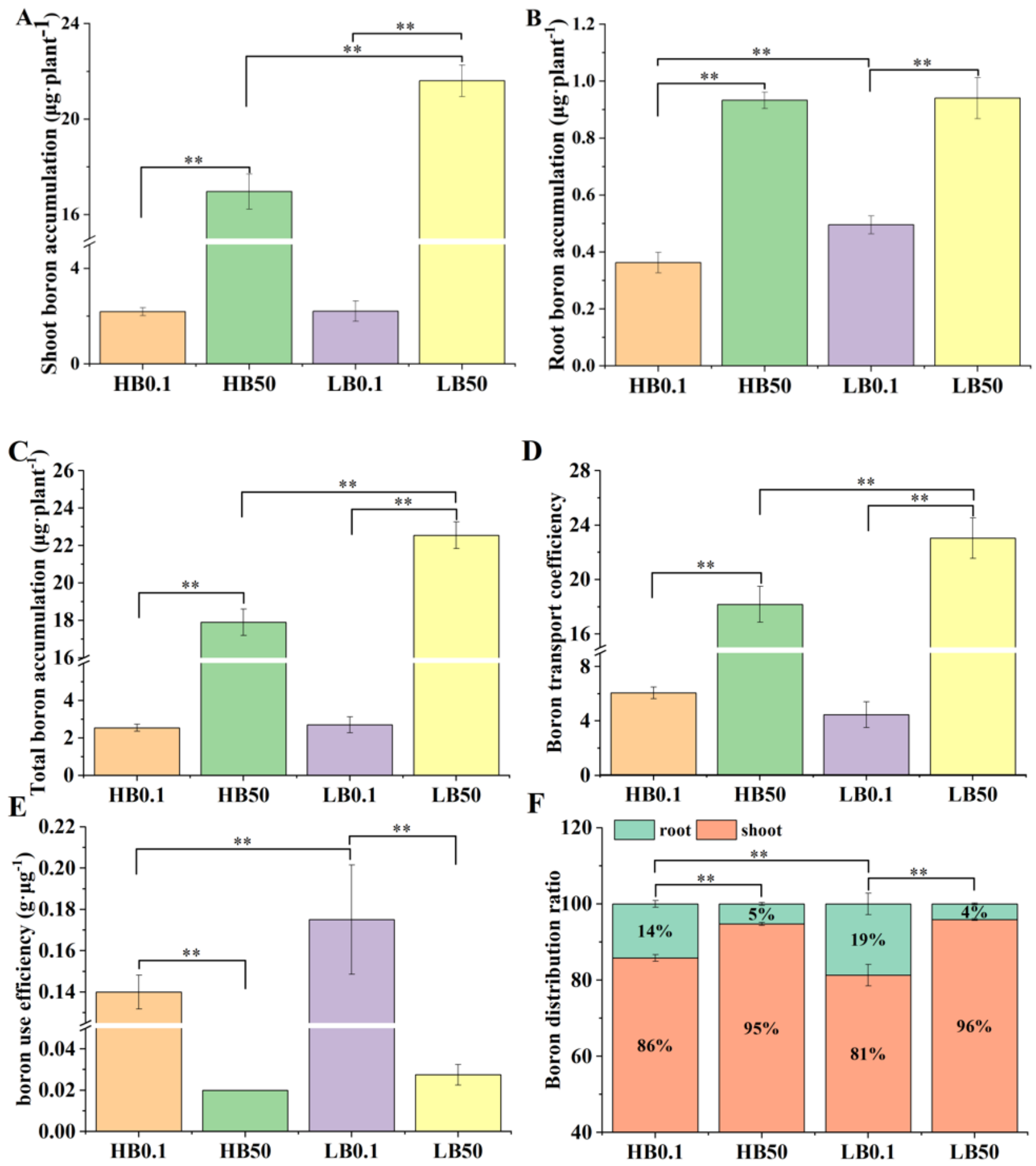

\section{Figure 5}

The effect of boron deficiency on (A) Shoot boron accumulation; (B) Root boron accumulation; (C) Total boron accumulation; (D) Boron transfer coefficient; (E) Boron use efficiency; $(F)$ Boron distribution rate. Error bars are represented by $\pm S D(n=3)$. Two-way ANOVA was used to analyze the significant differences between plants under different $B$ concentrations, with "*" indicating $p<0.05$, and "**" indicating $p<0.01$. 


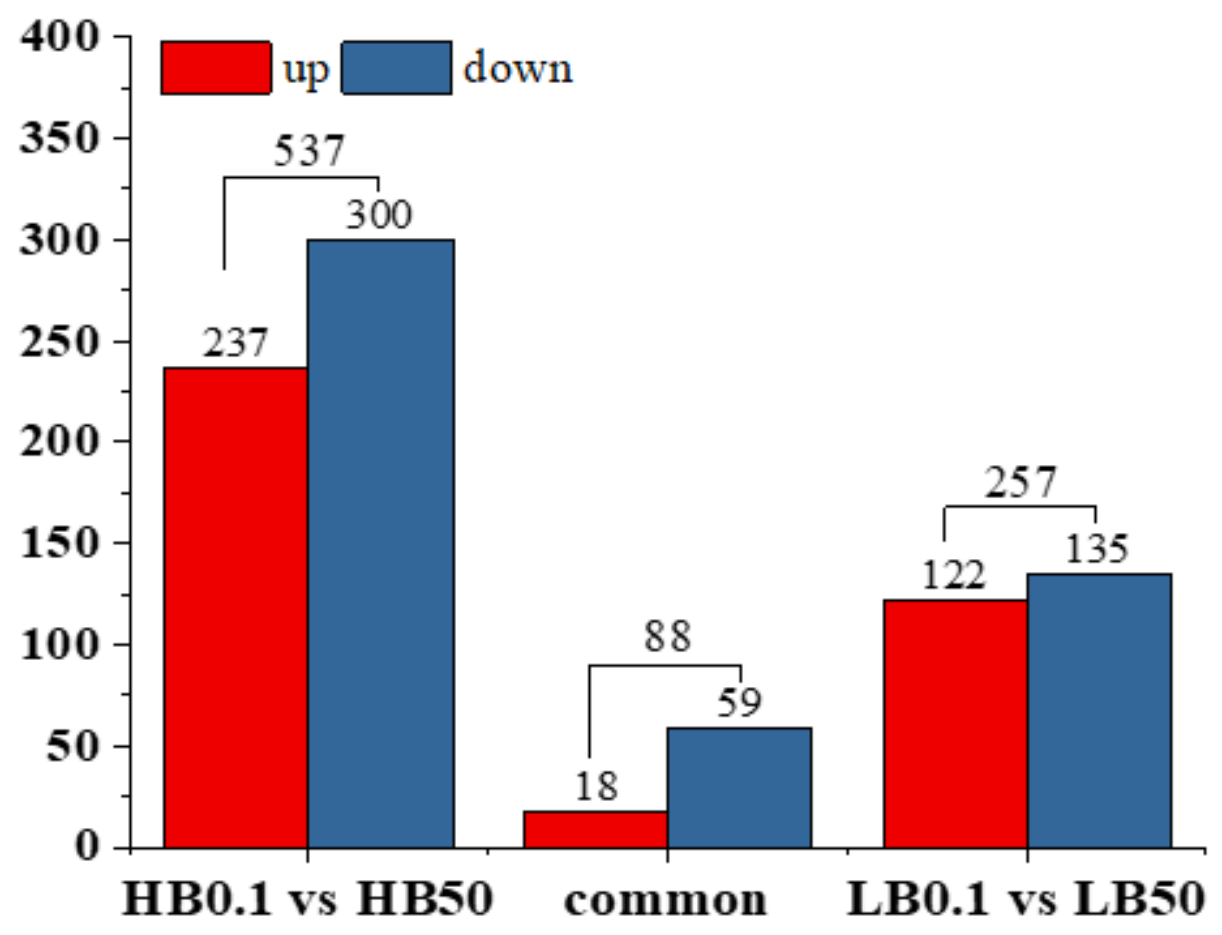

Figure 6

Comparison of DEGs in sugar beet variety with different boron efficiency under boron deficiency 
obsolete protein biosynthetic process inhibitor activity peptidase regulator activity peptidasc inhibitor activity
endopeptidase regulator activity endopeptidase inhibitor activity enzyme inhibitor activity calcium ion binding antioxidant activity

oxidoreductase activity, acting on peroxide as acceptor peroxidase activity metal ion binding cation binding
oxidoreductase activity nodulation oxygen transport gas transport

negative regulation of cellular biosynthetic process negative regulation of macromolecule biosynthetic process negative regulation of biosynthetic process negative regulation of protein metabolic process negative regulation of cellular protein metabolic process negative regulation of cellular amide metabolic process negative regulation of translation ôligopeptide transport response to drug cell wall organization or biogenesis drug transport
tion or biogenesis response to oxidative stress
response to stimulus response to stimulus

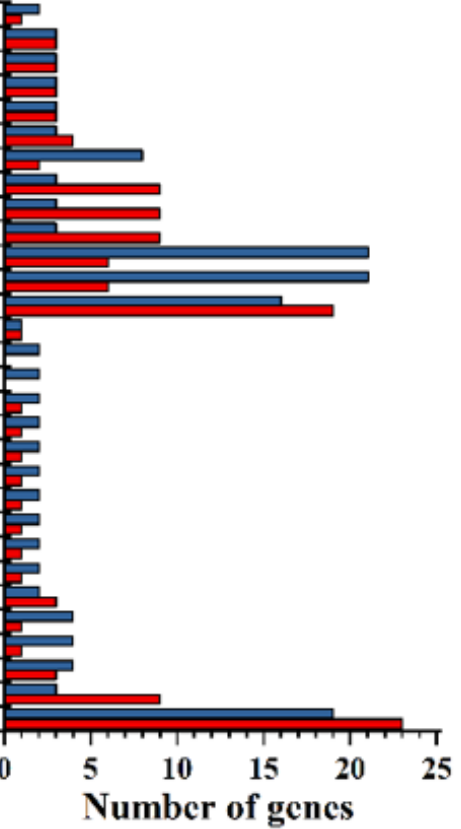

\section{molecular function}

B

\section{GO annotations analysis}

L. B0.I vs I,B50 up

LB0.1 vs LB50 dowm

metallocarboxypeptidase activity
obsolete protein biosynthetic process hydrolase actiyity, acting on glycosyl bonds hydrolase activity, hydrolyzing O-g ycosyl compounds transcription fáctor complex intracellular organelle lumen organelle lumen membrane-enclosed lumen nucleoplasm part nuclear lumen nuclear DNA-directed RNA polymerase complex RNA polymerase complex RNA polymerase II, holoenzyme DN $\Delta$-directed $\mathrm{RN} \Lambda$ polymerase complex RNA polymerase II transcription factor complex nuclear transcription factor complex transferase complex, transferring pliosphorus-containing groups negative regulation of cellular amide metabolic process
negative regulation of translation negative regulation of translation
ative regulation of cellular process negative regulation of cellular process
negative reguation of biological process
pathogenesis celldeath programmed cell death carbohydrate metabolic process

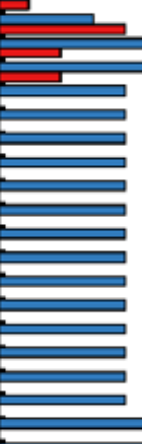

(2)
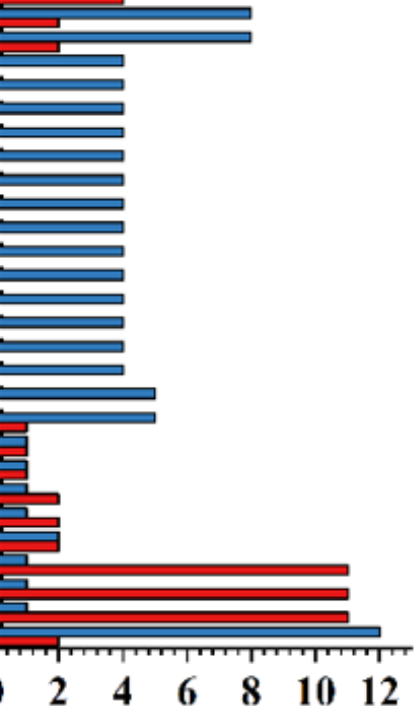

Number of genes

Figure 7

The $\mathrm{GO}$ term of different boron efficiency sugar beet varieties responds differently to boron deficiency (A) HB0.1 vs HB50 comparison group; (B) LB0.1 vs LB50 comparison group. 


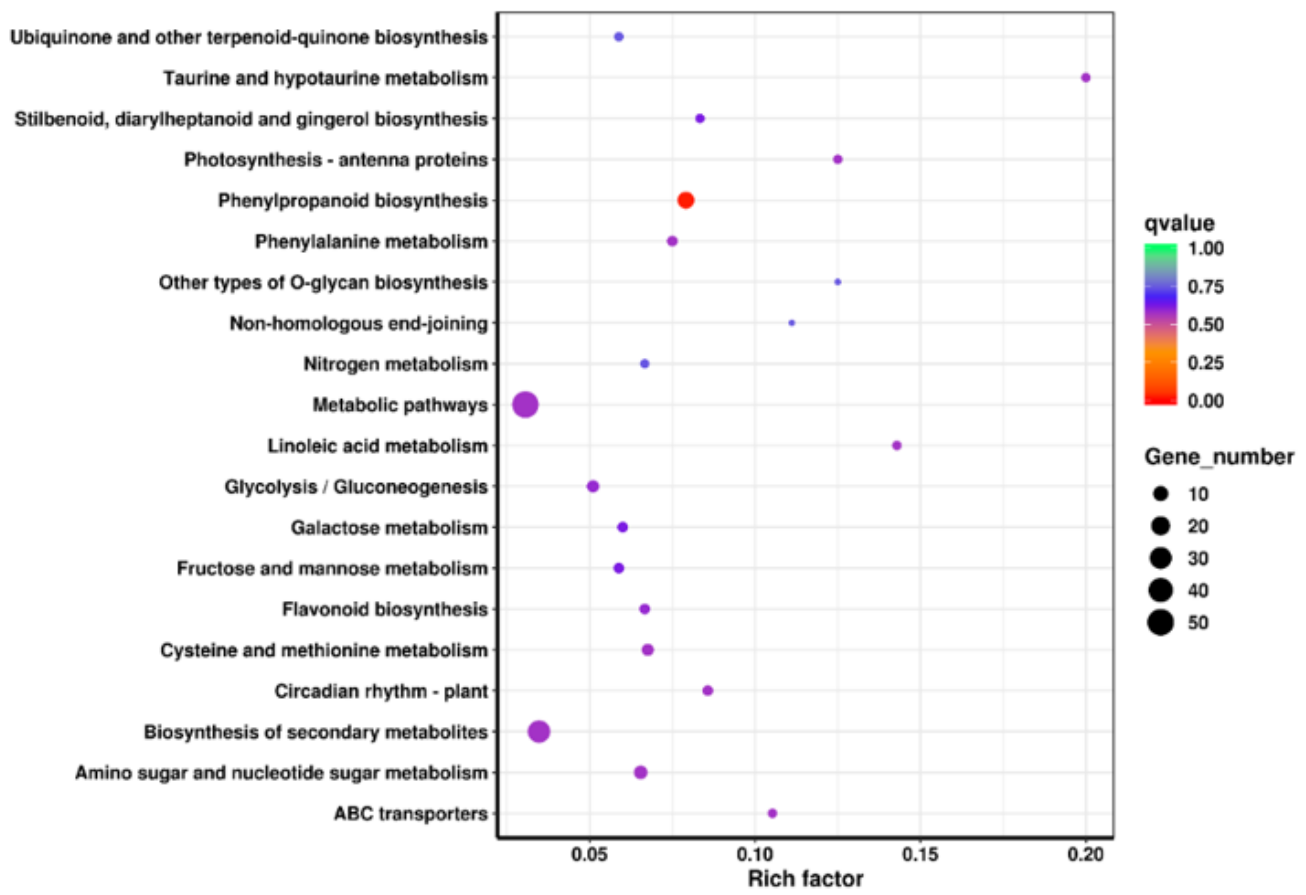

B

Statistics of pathway enrichment (LB0.1 vs LB50)

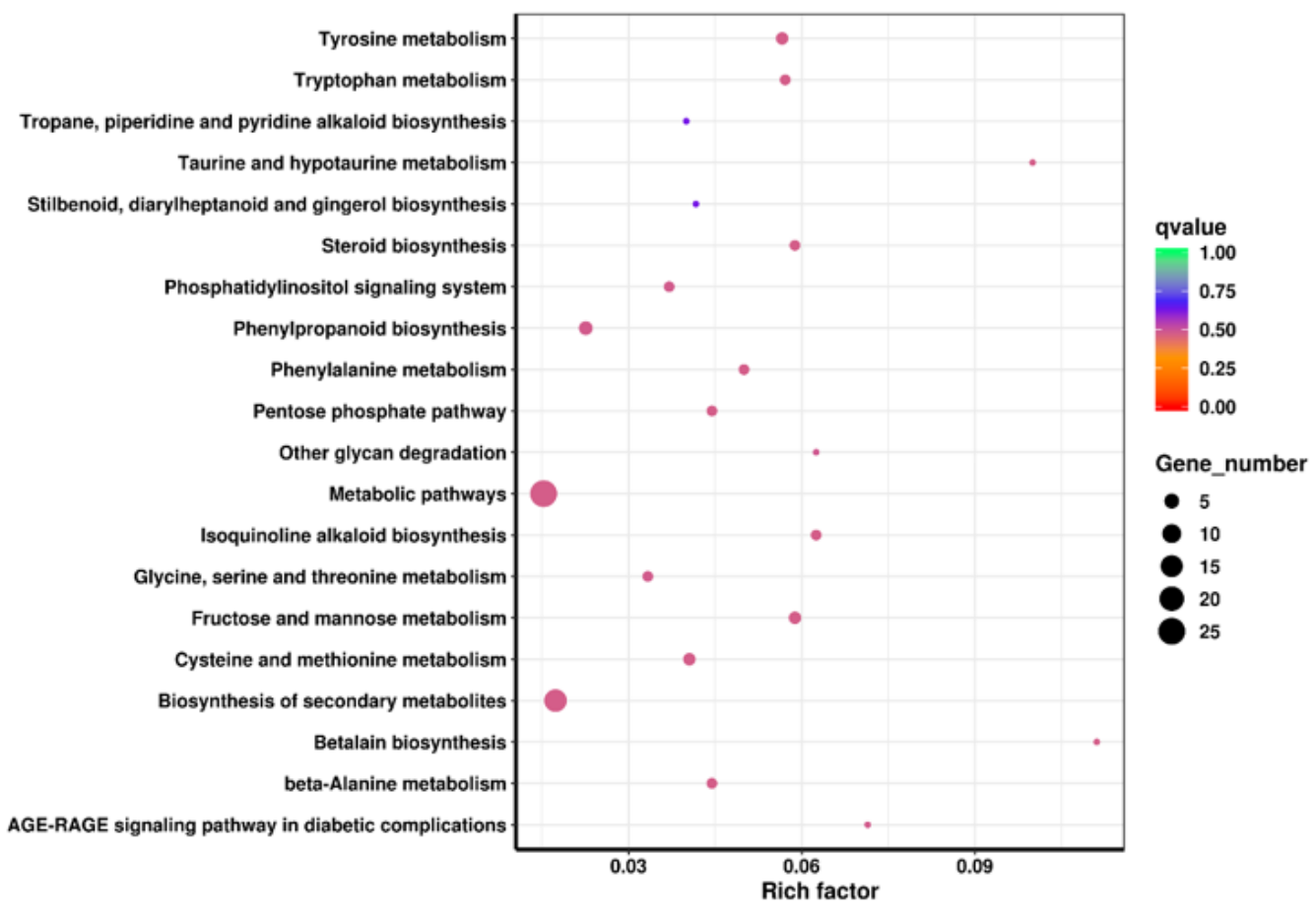

\section{Figure 8}

The effect of boron deficiency on the KEGG pathway in the roots of varieties with different boron efficiency, (A) HB0.1 vs HB50, (B) LB0.1 vs LB50. 
HB0.1vsHB50 LB0.1vsLB50 Gene ID Description

\begin{tabular}{|c|c|c|c|c|}
\hline \multirow{3}{*}{ SOD } & -0.860 & -0.953 & LOC104902979 & \multirow{3}{*}{$\begin{array}{l}\text { superoxide dismutase }[\mathrm{Cu}-\mathrm{Zn}] \text {, chloroplastic } \\
\text { superoxide dismutase }[\mathrm{Fe}], \text { chloroplastic-like } \\
\text { superoxide dismutase }[\mathrm{Mn}] \text {, mitochondrial }\end{array}$} \\
\hline & -0.199 & -0.177 & LOC104892465 & \\
\hline & 0.089 & -0.161 & LOC104887645 & \\
\hline \multirow{3}{*}{ POD } & 3.841 & 2.140 & LOC104908142 & \multirow{3}{*}{$\begin{array}{c}\text { peroxidase } 44 \\
\text { L-ascorbate peroxidase } 3 \text {, peroxisomal-like } \\
\text { L-ascorbate peroxidase } 3 \text {, peroxisomal }\end{array}$} \\
\hline & 1.542 & 0.669 & LOC104895312 & \\
\hline & 1.293 & 0.510 & LOC104895166 & \\
\hline CAT & 0.388 & 0.885 & LOC104905646 & catalase \\
\hline
\end{tabular}

Figure 9

The response of antioxidant enzyme-related genes to boron deficiency stress. The heat map shows the differential regulation of antioxidant enzymes such as SOD, POD and CAT in sugar beet varieties with different boron efficiency under boron deficiency. The red in the figure indicates that the gene is upregulated, and the blue indicates that the gene is down-regulated. The specific data indicates the relative expression of the gene Log2(fold change) (Log2(FC)).

HB0.1 vs HB50 LB0.1 vs LB50 Gene ID Description

\begin{tabular}{|c|c|c|c|c|}
\hline \multirow[t]{7}{*}{ bHLH } & 2.27 & -0.267 & LOC104889601 & transcription factor bHLH101-like \\
\hline & 2.918 & 0.972 & LOC104897425 & hypothetical protein \\
\hline & 2.277 & 0.503 & LOC104897819 & transcription factor bHLH18-like \\
\hline & 1.206 & 0.228 & LOC104897941 & HVA22-like protein a \\
\hline & 4.013 & 2.339 & LOC104898202 & probable terpene synthase 6 \\
\hline & 2.77 & 1.638 & LOC104898458 & cytochrome P450 94C1-like \\
\hline & 1.284 & 0.558 & LOC104900174 & WD repeat-containing protein DDB_G0292056 \\
\hline \multirow[t]{2}{*}{ WRKY } & 2.422 & 1.738 & LOC104883655 & probable WRKY transcription factor 71 \\
\hline & 0.974 & 1.307 & LOC104888477 & probable disease resistance protein RF9 \\
\hline \multirow[t]{4}{*}{ bZIP } & 2.219 & NA & LOC104887665 & putative UPF0481 protein At3g02645 \\
\hline & 0.788 & 0.06 & LOC104888761 & cellulose synthase-like protein G2 \\
\hline & 0.995 & -0.56 & LOC104888878 & auxin-binding protein ABP19a-like \\
\hline & 1.126 & 0.871 & LOC104905249 & hypothetical protein \\
\hline \multirow[t]{3}{*}{ MYB } & 0.976 & 0.203 & LOC104890147 & transcription factor GAMYB-like \\
\hline & 2.295 & 1.491 & LOC104895749 & malonyl-coenzyme:anthocyanin5-O-glucoside-6"'-O-malonyltransferase \\
\hline & 1.013 & 0.208 & LOC104904231 & protein EXORDIUM-like 5 \\
\hline \multirow[t]{5}{*}{ B3 } & 3.714 & 1.416 & LOC104888813 & cytosolic sulfotransferase 15 \\
\hline & 1.268 & 0.441 & LOC104889189 & protein SRG1 \\
\hline & 1.148 & 0.756 & LOC104892359 & molybdenum cofactor sulfurase \\
\hline & 2.071 & 1.51 & LOC104903279 & flavonol synthase/flavanone 3 -hydroxylase \\
\hline & 2.057 & 1.537 & LOC104908785 & cytochrome P450 82G1 \\
\hline
\end{tabular}

Figure 10

The effect of boron deficiency on the expression of transcription factor-related genes. The heat map showed the differential regulation of transcription factors such as bHLH, WRKY, bZIP, MYB and B3 and 
other related genes in sugar beet varieties with different boron efficiency under boron deficiency. The scale color represents $\log 2(\mathrm{FC})$, the red in the figure indicates that the gene is up-regulated, and the blue indicates that the gene is down-regulated.

HB0.1 vs HB50 LB0.1 vs LB50

Gene ID

Description

\begin{tabular}{|c|c|c|c|c|}
\hline \multirow{2}{*}{ NIP5-1 } & 1.980 & 1.945 & LOC104895986 & probable aquaporin NIP5-1 \\
\hline & 1.099 & 0.756 & LOC104895985 & probable aquaporin NIP5-1 \\
\hline NIP6-1 & 0.329 & 0.076 & LOC104904889 & probable aquaporin NIP6-1 \\
\hline NIP7-1 & -1.767 & -0.035 & LOC104906876 & probable aquaporin NIP7-1 \\
\hline B0R2 & 0.678 & 0.175 & LOC104894816 & probable boron transporter 2 \\
\hline \multirow{3}{*}{ B0R4 } & -0.199 & -0.478 & LOC104904596 & boron transporter 4 \\
\hline & -0.416 & 0.138 & LOC104904615 & boron transporter 4 \\
\hline & 0.270 & 2.367 & LOC104904614 & boron transporter 4 \\
\hline BOR7 & -2.544 & 2.433 & LOC104887698 & probable boron transporter 7 \\
\hline
\end{tabular}

Figure 11

The effect of boron deficiency on the expression of genes related to boron absorption and transporter. The heat map shows the differential regulation of Candidate genes related to boron uptake and transport such as NIP5-1, NIP6-1, NIP7-1, BOR2, BOR4 and BOR7 in sugar beet varieties with different boron efficiency under boron deficiency. The scale color represents Log2(FC), the red in the figure indicates that the gene is up-regulated, and the blue indicates that the gene is down-regulated.
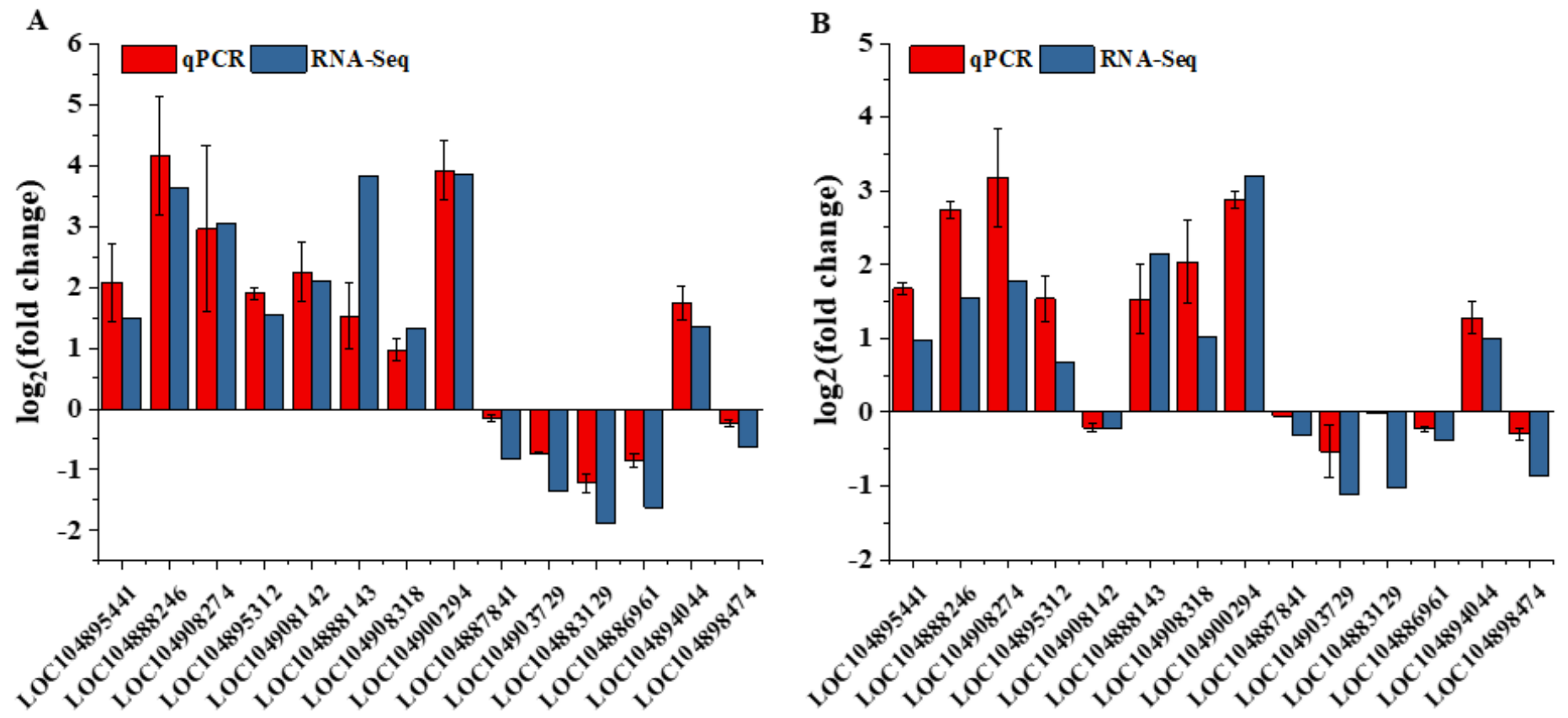

Figure 12 
Real-time PCR verification. (A)HB0.1 vs HB50; (B) LB0.1 vs LB50.

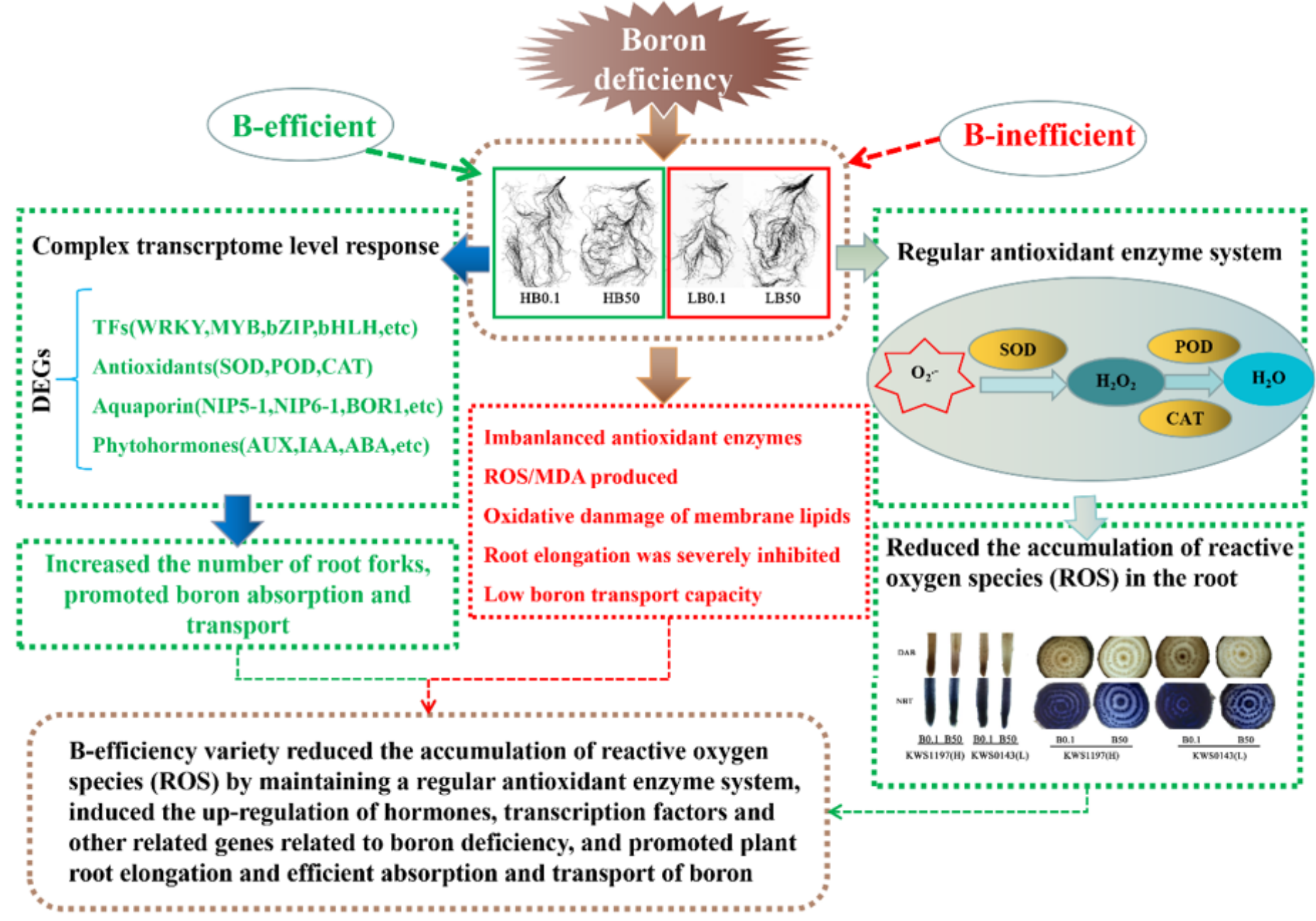

Figure 13

Schematic diagram of physiological and molecular mechanisms of efficient use of boron efficient variety. The seedlings of sugar beet varieties with different boron efficiency were cultivated in boric acid nutrient solution containing $0.1 \mu \mathrm{M}$ (boron deficiency) and $50 \mu \mathrm{M}$ (normal boron). The figure shows the difference in root morphology after 7 days of boron deficiency. It can be seen from the figure that the stress of boron deficiency leads to the disorder of the antioxidant system, which increases the MDA content and the accumulation of ROS in the root system, which in turn leads to oxidative damage and inhibits root elongation and normal growth. Boron efficient beet variety maintains a regular antioxidant system and regulates the up-regulated expression of related candidate genes such as transcription factors, transporters, boron transporters, and hormones, thereby increasing the ability of plants to absorb and transport boron and alleviate the symptoms of boron deficiency in beets.

\section{Supplementary Files}

This is a list of supplementary files associated with this preprint. Click to download. 
- Supplementarydata.docx

Page 34/34 